\title{
Complementary roles of retinoic acid and TGF- $\beta 1$ in coordinated expression of mucosal integrins by T cells
}

\author{
SG Kang ${ }^{1}$, J Park ${ }^{1}$, JY Cho ${ }^{1}$, B Ulrich ${ }^{1}$ and CH Kim ${ }^{1}$
}

$\alpha_{4}$ and $\beta_{7}$ integrins, such as $\alpha_{4} \beta_{1}, \alpha_{4} \beta_{7}$, and $\alpha_{E} \beta_{7}$, are major integrins required for migration of leukocytes into mucosal tissues. The mechanisms responsible for coordinated expression of these three integrins have been poorly elucidated to date. We report that expression of the Itg- $\alpha_{4}$ subunit by both CD4 ${ }^{+}$and CD8 ${ }^{+}$T cells requires the retinoic acid signal. In contrast, transcription of Itg- $\alpha_{\mathrm{E}}$ genes is induced by the transforming growth factor- $\beta 1$ (TGF $\beta 1$ ) signal. Expression of Itg- $\beta_{7}$ is constitutive but can be further increased by TGF $\beta 1$. Consistently, expression of $\alpha_{4}$-containing integrins is severely suppressed in vitamin A deficiency with a compensatory increase of $\alpha_{E} \beta_{7}$, whereas expression of Itg- $\alpha_{E}$ and Itg- $\beta_{7}$ is decreased in TGF $\beta$-signal deficiency with a compensatory increase in $\alpha_{4} \beta_{1}$. The retinoic acid-mediated regulation of $\alpha_{4}$ integrins is required for specific migration of T cells in vitro and in vivo. These results provide central regulatory mechanisms for coordinated expression of the major mucosal integrins.

\section{INTRODUCTION}

Integrin $\alpha_{4}$, a subunit of $\alpha_{4} \beta_{1}(\mathrm{CD} 49 \mathrm{~d}-\mathrm{CD} 29)$ and $\alpha_{4} \beta_{7}$, is a major target of intervention in treating inflammatory diseases through blocking leukocyte migration. ${ }^{1,2} \alpha_{4} \beta_{1}$, also known as VLA4 (very late antigen 4 ), is expressed by $\mathrm{T}$ cells, B cells, monocytes, and eosinophils. ${ }^{3,4} \alpha_{4} \beta_{7}$, once called lamina propria-associated molecule 1 , is expressed by T cells and B cells in mucosal tissues. ${ }^{5,6}$ $\alpha_{4} \beta_{1}$ and $\alpha_{4} \beta_{7}$ each bind its major counter receptor vascular cell adhesion molecule 1 (VCAM-1) and Mad CAM-1, respectively. $\alpha_{4} \beta_{7}$ also binds VCAM-1 and fibronectin, but at reduced affinity. ${ }^{7}$ The $\alpha_{4}$ integrins are involved in both rolling and firm adhesion of leukocytes on endothelial cells. ${ }^{8,9} \alpha_{4} \beta_{1}$ is involved in leukocyte migration to diverse tissues including mucosal tissues, bone marrow, splenic follicles, and inflamed tissues, whereas $\alpha_{4} \beta_{7}$ has a more specific role in lymphocyte migration to the gut and associated lymphoid tissues. ${ }^{10-14} \alpha_{E} \beta_{7}$, an integrin related to $\alpha_{4} \beta_{1}$ and $\alpha_{4} \beta_{7}$, binds E-cadherin expressed on epithelial cells. ${ }^{15} \alpha_{E} \beta_{7}$ is involved in the localization and function of both effector and regulatory T cells. ${ }^{16,17}$

Retinoic acid, such as all-trans retinoic acid (RA), is a vitamin A metabolite and highly produced by epithelial cells and dendritic cells in the small intestine. ${ }^{18}$ RA has a number of regulatory functions in the immune system. It is required for differentiation of promyelocytes into neutrophils. ${ }^{19-21}$ It promotes the generation of small intestine-homing $\mathrm{T}$ and B cells. ${ }^{22,23}$ In this regard, a severe paucity of $\mathrm{T}$ cells and immunoglobulin A-producing $B$ cells occurs in the intestine because of vitamin A deficiency. These functions of RA are consistent with the increased susceptibility of vitamin A-deficient subjects to a number of infectious microbial agents. ${ }^{24} \mathrm{RA}$ specifically induces the expression of a small intestine-homing chemokine receptor, chemokine (C-C motif) receptor 9 (CCR9), and a mucosal tissue-homing integrin molecule $\alpha_{4} \beta_{7}{ }^{22}$

It has been unclear how the mucosal integrins such as $\alpha_{4} \beta_{1}$, $\alpha_{4} \beta_{7}$, and $\alpha_{E} \beta_{7}$ are coordinately expressed. Through genomewide gene expression and functional studies, we identified that expression of the Itg- $\alpha_{4}$ chain in T cells requires RA, whereas optimal transcription of Itg- $\alpha_{E}$ and to a lesser degree Itg- $\beta_{7}$ genes requires the transforming growth factor- $\beta$ (TGF $\beta$ ) signal. We provide detailed evidence that functional expression of Itg- $\alpha_{4}-$ or Itg- $\alpha_{E}$-subunit-containing integrins by $T$ cells is coordinately regulated by RA and TGF $\beta 1$. The effect of the integrin regulation pathways on T-cell migration in physiological settings is discussed.

\footnotetext{
${ }^{1}$ Laboratory of Immunology and Hematopoiesis, Department of Comparative Pathobiology, The Purdue University Center for Cancer Research, Purdue University, West Lafayette, Indiana, USA. Correspondence: CH Kim (chkim@purdue.edu) 


\section{RESULTS}

RA selectively induces the transcription of $/ \mathrm{tg}-\alpha_{4}$ gene

To understand the function of RA in regulation of mucosal integrin expression in $\mathrm{T}$ cells, we activated naive $\mathrm{CD} 4^{+} \mathrm{T}$ cells in the presence of exogenous RA at a physiologically relevant concentration $(10 \mathrm{nM})$. As controls, we cultured the T cells without exogenous RA or in the presence of Ro41-5253 (a retinoic acid receptor- $\alpha(\mathrm{RAR} \alpha)$ antagonist; hereafter simply referred to as "Ro41") to block the effect of residual RA that is present in normal culture medium supplemented with $10 \%$ fetal bovine serum. It is estimated that $0.2-0.5 \mathrm{~nm}$ of RA is present in the culture medium because animal plasma-serum typically contains RA at $2-5 \mathrm{~nm} .{ }^{25}$ We performed a genome-wide microarray study and found that the Itg- $\alpha_{4}$ gene is highly induced by the serum-derived RA present in the culture medium at low concentrations (Figure 1a). Interestingly, the microarray data revealed that expression of Itg- $\beta_{1}$, Itg- $\beta_{7}$, and Itg- $\alpha_{E}$ was not significantly affected by different levels of RA (Figure 1b). We followed up the data with a real-time PCR assay and found that the $I t g-\alpha_{4}$ gene is responsive to RA in transcription, whereas the expression of Itg- $\beta_{1}$ and Itg- $\beta_{7}$ was not significantly affected by the presence or absence of the RA signal (Figure 1c). Itg- $\alpha_{4}$ transcription was further increased by exogenous RA at 1 and $10 \mathrm{~nm}$. Interestingly, the real-time PCR assay revealed that Itg- $\alpha_{E}$ mRNA was upregulated when Ro41 was used, which the microarray study failed to reveal.

We performed a chromatin immunoprecipitation assay to assess the potential binding of nuclear RAR $\alpha$ to the regulatory region of the Itg- $\alpha_{4}$ gene. On the basis of the DNA sequence analysis, we found a total of seven putative retinoic acid response elements (RAREs). The chromatin immunoprecipitation assay revealed that one of the putative RAREs is a real binding site for RAR $\alpha$ (Figure 1d). RA enhanced the binding whereas Ro41 decreased the binding.

In addition to $\operatorname{Itg}-\alpha_{4}$, many genes are up- or downregulated in T cells in response to RA. These genes are listed in Table 1 and in Supplementary Figure S1 online. Induction of CCR9 by RA, as reported previously, ${ }^{22}$ was clearly detectable. We confirmed by a real-time PCR method that growth hormone-regulated TBC protein 1 (GRTP1), cytochrome P450, family 26, subfamily b, polypeptide 1 (CYP26B1), dehydrogenase-reductase member 3 (DHRS3), and leucine zipper transcription factor-like 1 (LZTFL1) are induced by RA, whereas serine (or cysteine) proteinase inhibitor clade B member 1a (SERPINB1) is suppressed by RA (Supplementary Figure S1 online). GRTP1 is a GTPase activating protein that increases GTPase activity of Rab3A. ${ }^{26}$ CYP26B1 is a cytochrome $P 450$ that catabolizes RA. ${ }^{27}$ DHRS3 is an enzyme that mediates the first oxidative conversion of retinol into retinal. ${ }^{28}$ LZTFL1 is a putative transcription factor with a leucine zipper domain and is a part of a transcriptional map that includes the CCR9 gene. ${ }^{29}$ SERPINB1 is an inhibitor of serine proteases such as elastase, cathepsin G, and proteinase- $3 .{ }^{30}$ We focused our study in this report on regulation of the major mucosal integrins including Itg- $\alpha_{4}$.
T-cell activation in the presence of RA induces surface expression of both $\alpha_{4} \beta_{1}$ and $\alpha_{4} \beta_{7}$

Surface expression of integrins involves heterodimerization of integrin $\alpha$ and $\beta$ subunits, and therefore simple expression of one subunit is not sufficient for its expression on the cell surface. It is a question of interest whether the $\alpha_{4}$ subunit induced by RA is required for all $\alpha_{4}$ subunit-containing integrins. We examined whether RA would have significant effects on surface expression of $\alpha_{4} \beta_{1}$ and $\alpha_{4} \beta_{7}$ (Figure 2a). T cells activated in the presence of Ro41 lost expression of Itg- $\alpha_{4}$. In contrast, Itg- $\beta_{1}$ was expressed at high levels even with Ro41. Surface expression of Itg- $\beta_{7}$ was enhanced with RA. Induction of surface Itg- $\alpha_{4}$ expression by RA is independent of exogenous TGF $\beta 1$ in culture. Itg- $\alpha_{E}$ expression was not significantly changed by RA alone but increased with exogenous TGF $\beta 1$. These results, together with the regulation at the RNA level (Figure 1c), suggest that RA-dependent induction of Itg- $\alpha_{4}$ gene transcription is a driving force in the surface expression of both Itg- $\beta_{7}$ and Itg- $\beta_{1}$.

We also assessed the expression of the $\alpha_{4} \beta_{7}$ heterodimer complex with the DATK32 antibody (Figure $2 \mathbf{b}$ ). By gating out the $\alpha_{4} \beta_{7}{ }^{+}$cells, expression of the $\alpha_{4} \beta_{1}$ complex by $\alpha_{4} \beta_{7}{ }^{-}$T cells was also determined. It was apparent that expression of both $\alpha_{4} \beta_{7}$ and $\alpha_{4} \beta_{1}$ was increased in response to the RA signal.

To gain more insights into the RAR receptor usage, we used additional RAR agonists and antagonists such as LE540 (panRAR antagonist), CD2665 (RAR- $\beta / \gamma$ antagonist), AM580 (RAR $\alpha$ agonist), and AC55649 (RAR $\beta 2$ agonist) along with RA (panRAR agonist) and Ro41 (RAR $\alpha$ antagonist; Figure 2c). Although both AM580 and AC55649 induced the expression of Itg- $\alpha_{4}$, AM580 was more potent even at a lower dose (20 nM). Ro41 was more potent than CD2665. LE540 was most potent in the induction of Itg- $\beta_{7}$ and Itg- $\alpha_{\mathrm{E}}$. Overall, this information suggests that both the RAR $\alpha$ and $\mathrm{RAR} \beta / \gamma$ receptors can regulate expression of the integrins, but RAR $\alpha$ seems to have a larger role.

Flow cytometric determination of the perfect coexpression of Itg- $\alpha_{E}$ and Itg- $\beta_{7}$ or Itg- $\alpha_{4}$ and Itg- $\beta_{7}$ revealed sharp needle-like double-positive populations that may be viewed as the result of autofluorescence or miscompensation in flow cytometry. Using appropriate isotype controls, we confirmed that these doublepositive cells indeed have perfect coexpression of integrin subunits (Supplementary Figure S2 online).

Regular fetal bovine sera contain biologically active RA. We performed a similar culture experiment in a serum-free medium to rule out the effect of the residual RA (Supplementary Figure S3 online). We confirmed that RA induces Itg- $\alpha_{4}$. The $\mathrm{T}$ cells of the control group expressed Itg- $\alpha_{4}$ at levels similar to those of the Ro41-treated group. This rules out the possibility that the decreased Itg- $\alpha_{4}$ expression by Ro41 in a regular medium is because of an unexpected agonistic effect of Ro41.

We further examined the stability of the expressed integrins induced by RA using cycloheximide, a protein biosynthesis inhibitor (Supplementary Figure S4 online). We found that the induced integrins $\left(\alpha_{4} \beta_{7}\right.$, Itg- $\alpha_{4}$, Itg- $\beta_{7}$, Itg- $\beta_{1}$, and Itg- $\left.\alpha_{E}\right)$ were stable on the cell surface for at least $12 \mathrm{~h}$ after the treatment of cycloheximide. 


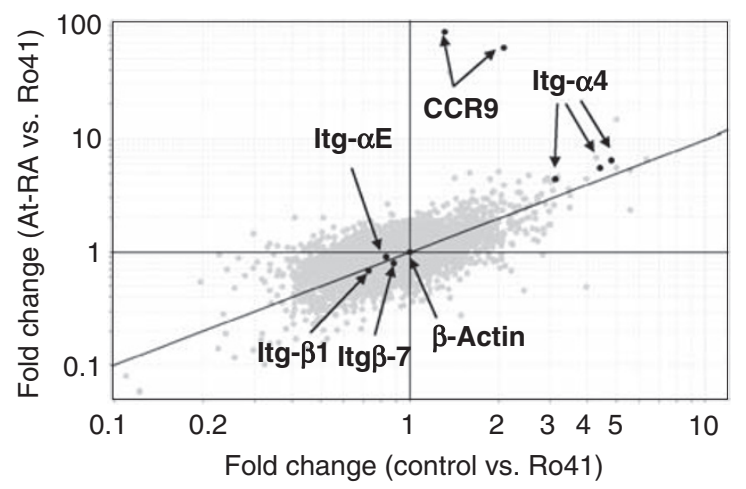

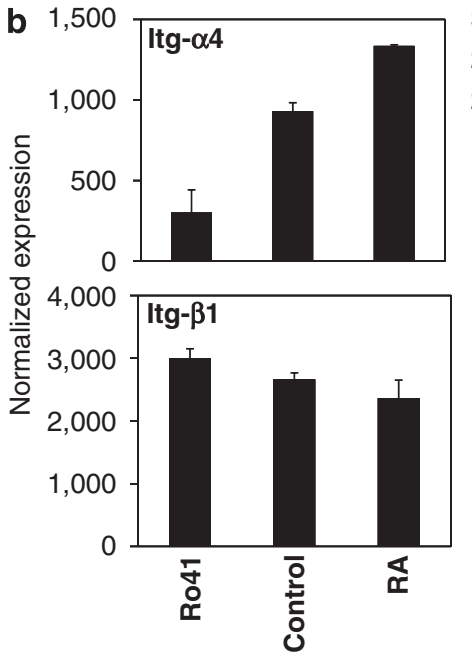
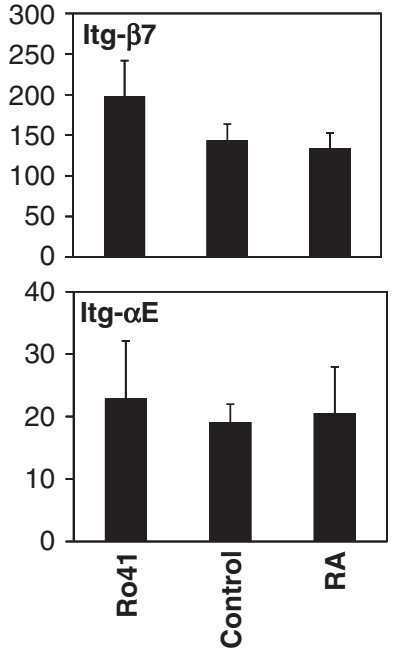

C

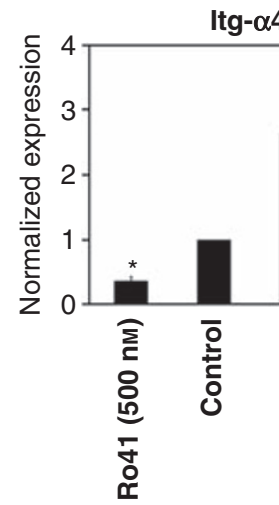

d

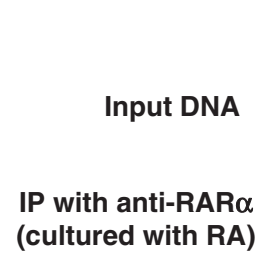

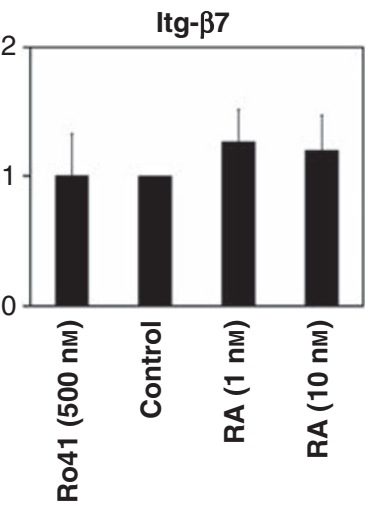

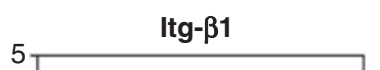

10

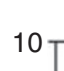

$\operatorname{ltg}-\alpha E$
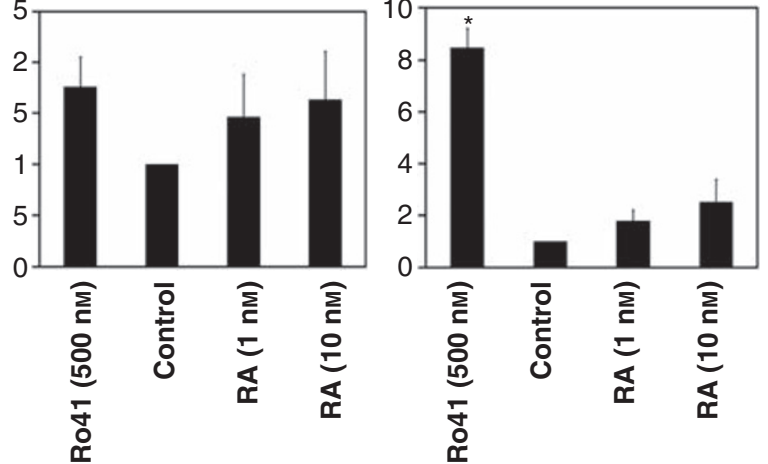

RARE7 RARE6 RARE4/5 RARE3 RARE2 RARE1

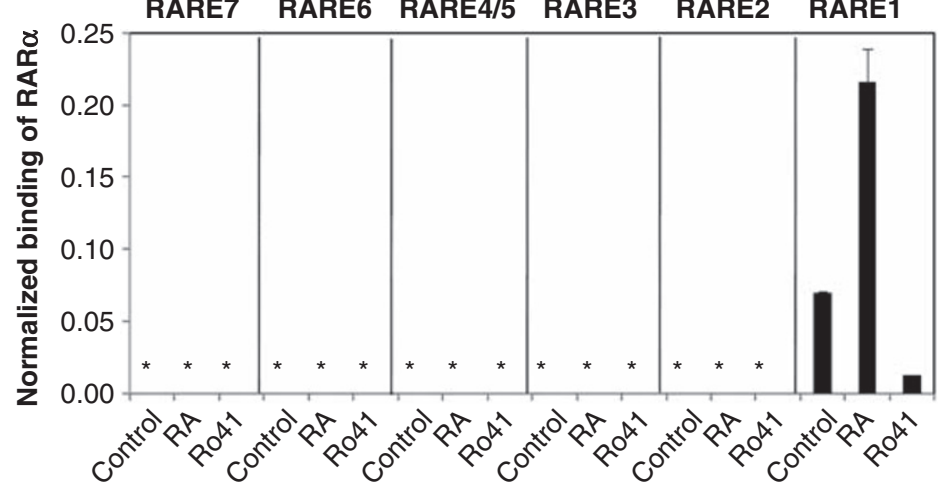

Putative RAREs
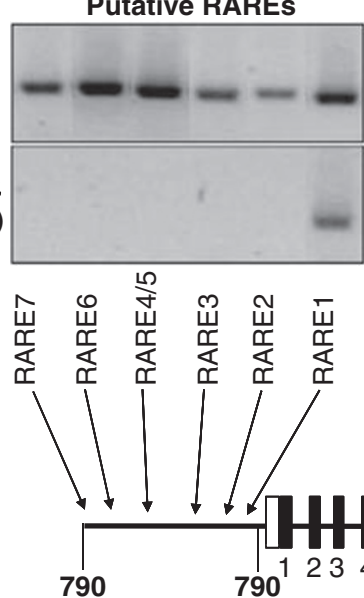

790

87,941

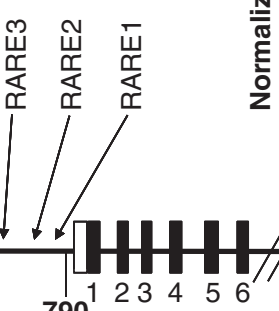

790

95,731

Mouse Itg- $\alpha / C D 49 D$ gene in chromosome 2

Figure 1 Retinoic acid (RA)- and retinoic acid receptor- $\alpha$ (RAR $\alpha$ )-dependent transcription of the Itg- $\alpha_{4}$ gene, but not Itg- $\beta_{7}$, Itg- $\beta_{1}$, and $\operatorname{ltg}$ - $\alpha_{E}$ genes in $\mathrm{CD}^{+} \mathrm{T}$ cells. (a) A dot plot showing genes upregulated in response to high and low concentrations of RA. An Affymetrix microarray was used to determine the levels of gene expression. The $x$ axis represents fold changes in gene expression between CD4 ${ }^{+} T$ cells activated in control medium (containing low levels of RA) and CD4 ${ }^{+} T$ cells cultured in the presence a RAR $\alpha$ antagonist (Ro41-5253, abbreviated as "Ro41"). The $y$ axis represents fold changes in gene expression between CD4 ${ }^{+} T$ cells activated with exogenous RA (10nm) and CD4+ T cells cultured in the presence a RAR $\alpha$ antagonist (Ro41-5253). (b) Expression levels of integrin genes based on the microarray data. Error bars are differences between two independent array data sets. (c) Real-time PCR analysis of gene expression. Combined data of four independent sets are shown. The data are expressed relative to control T cells. *Significant differences from the controls. (d) Binding of RAR $\alpha$ to retinoic acid response elements (RAREs) in the 5' upstream regulatory region of the Itg- $\alpha_{4}$ gene. A chromatin immunoprecipitation (ChIP) assay was performed to determine RAR $\alpha$ binding to RARE candidates on the 5' upstream regulatory region of the $\mathrm{Itg}-\alpha_{4}$ gene. RA (10nM) was used. A representative data set from three independent experiments is shown. ${ }^{*}$ Undetectable. 
Table 1 T-cell genes regulated by RA at different RA conditions

\begin{tabular}{|c|c|c|c|c|c|}
\hline Name & Affymetrix ID & GenBank ID & RA/Ro & Con/Ro & RA/Con \\
\hline \multicolumn{6}{|c|}{ RA upregulated genes } \\
\hline Ccr9 & 1427419_x_at & NM_009913 & 86.85 & 1.31 & 66.08 \\
\hline Ccr9 & 1421920_a_at & NM_009913 & 63.05 & 2.09 & 30.14 \\
\hline Cyp26b1 & 1460011_at & NM_175475 & 38.08 & 1.36 & 27.87 \\
\hline 1810011H11Rik & 1429604_at & NM_001163616 & 22.39 & 10.64 & 2.10 \\
\hline Grtp1 & 1425891_a_at & NM_025768 & 17.11 & 27.07 & 2.07 \\
\hline Grtp1 & 1439150_x_at & NM_025768 & 14.57 & 5.03 & 2.89 \\
\hline$P 2 r x 7$ & 1419853_a_at & NM_0010388397 & 11.92 & 10.61 & 1.12 \\
\hline$P 2 r x 7$ & 1439787_at & NM_001038839 & 10.70 & 8.48 & 1.26 \\
\hline Dhrs3 & 1448390_a_at & NM_011303 & 6.87 & 4.27 & 1.60 \\
\hline Osgin 1 & 1424022_at & NM_027950 & 6.56 & 6.31 & 1.04 \\
\hline Laptm5 & 1459841_x_at & NM_010686 & 6.49 & 3.19 & 2.03 \\
\hline Cerkl///Itga4 & 1456498_at & NM_010576 & 6.48 & 4.82 & 1.34 \\
\hline Fam102b & 1455033_at & NM_001163567 & 5.53 & 5.00 & 1.10 \\
\hline Cerkl///Itga4 & 1450155_at & NM_010576 & 5.49 & 4.41 & 1.24 \\
\hline Fam102b & 1434828_at & NM_001163567 & 5.30 & 5.58 & 0.94 \\
\hline Nrp1 & 1448943_at & NM_008737 & 4.81 & 2.52 & 1.90 \\
\hline Art2b & 1420794_at & NM_019915 & 4.70 & 3.15 & 1.49 \\
\hline Adam19 & 1418403_at & NM_009616 & 4.59 & 2.93 & 1.56 \\
\hline Lztfl1 & 1417170_at & NM_033322 & 4.47 & 3.97 & 1.12 \\
\hline$N+5 e$ & 1428547_at & NM_011851 & 4.47 & 3.97 & 1.12 \\
\hline Cerkl///Itga4 & 1436037_at & NM_010576 & 4.44 & 3.09 & 1.43 \\
\hline Adam19 & 1418402_at & NM_009616 & 4.35 & 2.88 & 1.51 \\
\hline Sorcs2 & 1419358_at & NM_030889 & 4.34 & 2.86 & 1.51 \\
\hline Cd38 & 1433741_at & NM_007646 & 4.32 & 3.02 & 1.42 \\
\hline Trim16 & 1452362_at & NM_053169 & 4.18 & 2.33 & 1.79 \\
\hline Nrgn & 1423231_at & NM_022029 & 4.16 & 3.02 & 1.37 \\
\hline Hic1 & 1449226_at & NM_001098203 & 3.60 & 3.47 & 1.03 \\
\hline Siglec5 & 1424975_at & NM_145581 & 3.48 & 3.06 & 1.13 \\
\hline Tnfsf11 & 1419083_at & NM_011613 & 3.28 & 2.79 & 1.17 \\
\hline Pank3 & 1426259_at & NM_145962 & 3.15 & 3.49 & 0.90 \\
\hline Gm13305 & 1459868_x_at & NM_001099348 & 3.11 & 2.70 & 1.15 \\
\hline Golga1 & 1432054_at & NM_029793 & 2.92 & 2.69 & 1.08 \\
\hline Cldn10 & 1426147_s_at & NM_001160096 & 2.76 & 2.70 & 1.02 \\
\hline Stk17b & 1430165_at & NM_133810 & 2.69 & 2.88 & 0.93 \\
\hline Pvt1 & 1450541_at & NR_003368 & 2.62 & 2.56 & 1.02 \\
\hline Myo1e & 1428509_at & NM_181072 & 2.60 & 3.08 & 0.84 \\
\hline D5Wsu178e & 1442069_at & NM_027652 & 2.47 & 3.48 & 0.71 \\
\hline Prg2 & 1422873_at & NM_008920 & 2.36 & 5.57 & 0.42 \\
\hline Gucy1a3 & 1420533_at & NM_021896 & 2.23 & 2.64 & 0.84 \\
\hline \multicolumn{6}{|c|}{ RA downregulated genes } \\
\hline Tph1 & 1419524_at & NM_001136084 & 0.05 & 0.12 & 0.48 \\
\hline Cma1 & 1449456_a_at & NM_010780 & 0.07 & 0.11 & 0.71 \\
\hline Serpinb1a & 1416318_at & NM_025429 & 0.10 & 0.32 & 0.31 \\
\hline Nacc2 & 1417153_at & NM_001037098 & 0.11 & 0.25 & 0.45 \\
\hline 1110001D15Rik & 1429582_at & NM_001037098 & 0.13 & 0.29 & 0.46 \\
\hline
\end{tabular}


Table 1 Continued

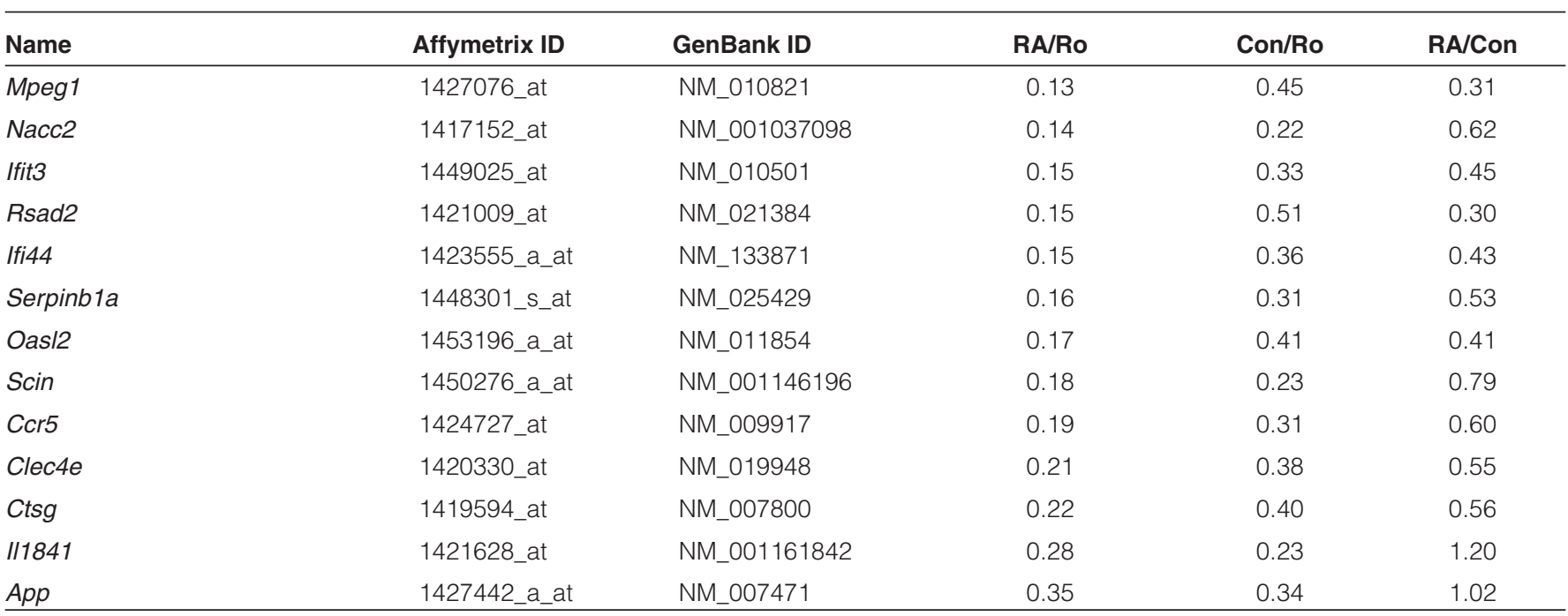

Naive CD4 ${ }^{+}$T cells were cultured in three different conditions containing 10 nm retinoic acid (RA), no exogenous RA (Con; low levels of residual RA present in the medium containing 10\% fetal bovine serum (FBS)), and Ro41 (Ro; a retinoic acid receptor- $\alpha$ (RAR $\alpha$ ) antagonist to block the effect of residual RA on RAR $\alpha$ ). Expression ratios of genes that are up- or downregulated in three different comparisons are shown. The raw and processed data are deposited at the Gene Expression Omnibus (GEO) array data base (www.ncbi.nlm.nih.gov/geo; the accession number is GSE20500).

\section{T-cell expression of Itg- $\alpha_{4}$ is decreased in vitamin A deficiency}

To confirm the regulatory role of RA in vivo, we induced vitamin A deficiency in mice and determined the expression of the integrins. We examined the integrin expression phenotype of T cells in the small intestine and spleen (a non-intestinal tissue). In the spleen, Itg- $\alpha_{4}$ was greatly decreased on both FoxP ${ }^{-}$and FoxP3 ${ }^{+} \mathrm{CD}^{+}{ }^{+} \mathrm{T}$ cells in vitamin A-deficient mice compared with control mice (Figure 3a). This decrease was relatively more severe on FoxP3 ${ }^{+}$T cells compared with FoxP3 ${ }^{-} \mathrm{T}$ cells. Itg- $\beta_{1}$ expression was not affected by different vitamin A status. Itg- $\beta_{7}$ was, unexpectedly, induced in vitamin A deficiency. In the small intestine, Itg- $\alpha_{4}$ was again decreased in vitamin $A$ deficiency with almost no or minor change in the expression of Itg- $\beta_{1}$ (Figure $3 \mathbf{b}$ ). Itg- $\beta_{7}$ was again strongly induced in vitamin A deficiency in the small intestine.

Increased surface expression of Itg- $\beta_{7}$ in vitamin A deficiency is a mystery given the current perception that RA would induce Itg- $\beta_{7}$ expression. We hypothesize that the enhanced expression of Itg- $\beta_{7}$ in vitamin A deficiency would be the result of an increased expression of it's other dimerization partner, Itg- $\alpha_{\mathrm{E}}$, in vitamin A deficiency. When we examined the expression of Itg- $\alpha_{E}$ and Itg- $\beta_{7}$, it was clear that most Itg- $\beta_{7}$ molecules were coexpressed on $T$ cells with the Itg- $\alpha_{E}$ molecules in vitamin A deficiency (Figure 3c, d). This coexpression was evident on T cells in both spleen and small intestine. The tight coexpression of Itg- $\alpha_{E}$ and Itg- $\beta_{7}$ suggests that two subunits are probably complexed together in the same cells. Again, this regulation in vitamin A deficiency occurs on both FoxP3 ${ }^{+}$and FoxP3$\mathrm{T}$ cells. Overall, there is a clear change from T cells expressing $\alpha_{4} \beta_{1}$ and $\alpha_{4} \beta_{7}$ in the mice with normal vitamin $A$ status to those expressing $\alpha_{E} \beta_{7}$ in vitamin A deficiency (Supplementary Figure S5 online).
The TGF $\beta$ signal is required for functional expression of Itg- $\beta_{7}$ and Itg- $\alpha_{E}$

A question critical for expression of both $\alpha_{4} \beta_{7}$ and $\alpha_{E} \beta_{7}$ is what would regulate the transcription of the $\operatorname{Itg}-\beta_{7}$ gene. TGF $\beta$ is implicated in upregulation of Itg- $\beta_{7}$ in a cytotoxic lymphoma cell line. ${ }^{31}$ We examined whether the TGF $\beta$ signal is required for expression of Itg- $\beta_{7}$ in primary $\mathrm{CD}_{4}{ }^{+} \mathrm{T}$ cells using $\mathrm{T}$ cells isolated from transgenic mice expressing a dominant negative form of TGF $\beta$ RII (dnTGF $\beta$ RII mice). ${ }^{32}$ The T cells in these mice are largely defective in reception of the TGF $\beta$ signal. Naive T cells from the dnTGF $\beta$ RII mice were ineffective in surface expression of Itg- $\beta_{7}$ in response to RA, whereas expression of Itg- $\alpha_{4}$ was induced normally (Figure 4a). The induction of Itg- $\beta_{7}$ on wild-type FoxP3 ${ }^{+} \mathrm{T}$ cells was even higher, whereas it was defective on the transgenic FoxP ${ }^{+} \mathrm{T}$ cells in the presence of exogenous TGF $\beta 1$. In addition, we observed that the surface expression of Itg- $\alpha_{\mathrm{E}}$ and Itg- $\beta_{7}$ was induced in response to TGF $\beta 1$ and Ro41 on wild-type but not on the transgenic T cells (Figure 4a). CD103- $\alpha \mathrm{E} \beta 7$, induced by TGF $\beta 1$ as determined in this study, is commonly viewed as a FoxP3 ${ }^{+}$ T cell-specific marker. We would like to point out that this is not accurate, because the majority of $\mathrm{CD} 4{ }^{+} \mathrm{CD} 103^{+} \mathrm{T}$ cells in non-lymphoid tissues such as the lung and intestine are FoxP3 ${ }^{-}$ T cells (Supplementary Figure S6 online). Moreover, even $\mathrm{CD}^{+}{ }^{+}$FoxP3 $^{-} \mathrm{T}$ cells, differentiated in vitro in the presence of TGF $\beta 1$, highly expressed CD103 (Figure 4a).

We next determined the expression levels of mRNA for Itg$\alpha_{E}$ and Itg- $\beta_{7}$ in the wild-type and dnTGF $\beta$ RII T cells cultured with RA or Ro41. We observed that dnTGF $\beta$ RII T cells fail to express Itg- $\alpha_{\mathrm{E}}$ and Itg- $\beta_{7}$ transcripts (Figure $4 \mathbf{b}$ ). These results show that the TGF $\beta 1$ signal is required for expression of Itg- $\beta_{7}$ and Itg- $\alpha_{E}$ at the RNA level. 
To gain insights into the function of the TGF $\beta$ signal in vivo, we determined the integrin expression phenotype of the T cells from dnTGF $\beta$ RII mice. We found that expression of Itg- $\alpha_{E}$ and Itg- $\beta_{7}$ was decreased on $\mathrm{CD} 4^{+} \mathrm{T}$ cells in the spleen, small intestine, and large intestine (Figure $\mathbf{4 c}$ ). Instead, there were increases in T cells expressing $\alpha_{4} \beta_{1}$, which seems to be a compensatory response to the Itg- $\beta_{7}$ decrease (Figure $4 \mathbf{d}$ ). $\mathrm{CD}^{+}{ }^{+} \mathrm{T}$ cells were highly similar to $\mathrm{CD} 4^{+} \mathrm{T}$ cells in expression of the integrins in dnTGFßRII mice.

\section{Regulation of the integrins in $\mathrm{CD}^{+} \mathrm{T}$ cells}

The results in Figure $4 \mathbf{c}$, $\mathbf{d}$ on $\mathrm{CD} 8^{+} \mathrm{T}$ cells show that optimal expression of $\alpha_{\mathrm{E}} \beta_{7}$ requires the TGF $\beta$ signal. We determined further whether expression of Itg- $\alpha_{4}$ and other Itg chains is induced by RA in $\mathrm{CD}^{+} \mathrm{T}$ cells. Similar to $\mathrm{CD} 4^{+} \mathrm{T}$ cells, Itg- $\alpha_{4}$ was strongly induced in response to RA (Figure 5a). Expression of Itg$\alpha_{\mathrm{E}}$ and Itg- $\beta_{7}$ was induced in response to TGF $\beta 1$. The overall Itg expression pattern of the $\mathrm{CD} 8^{+} \mathrm{T}$ cells cultured in a serum-free medium was similar to that cultured in a serum-containing a

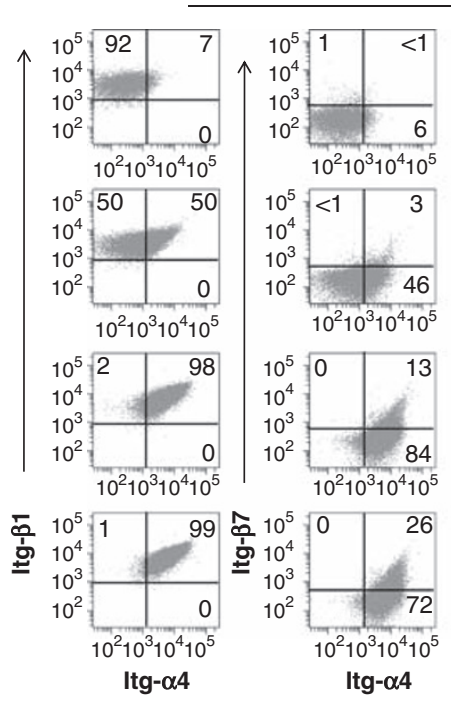

$\mathrm{CD4}^{+} \mathrm{FoxP}^{-}$
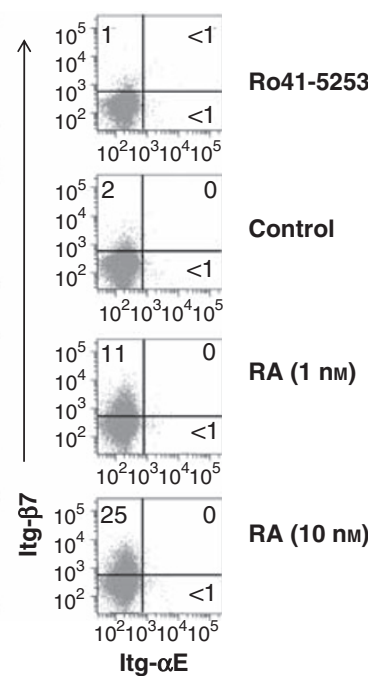

$\mathrm{CD}^{+}{ }^{+} \mathrm{FoxP}^{+}$

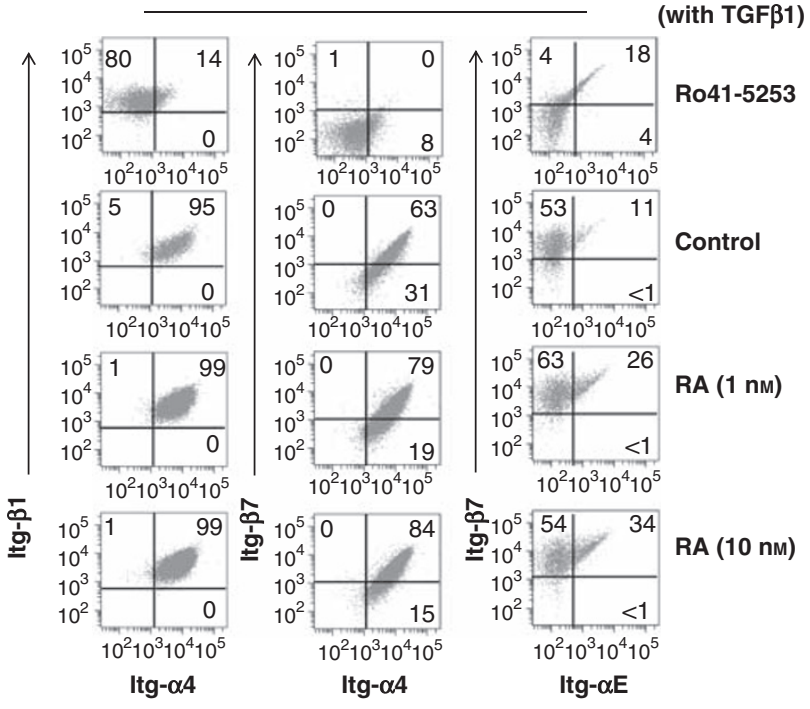

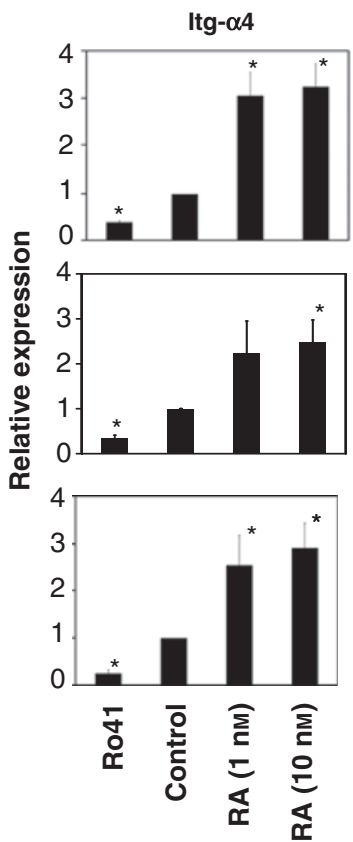
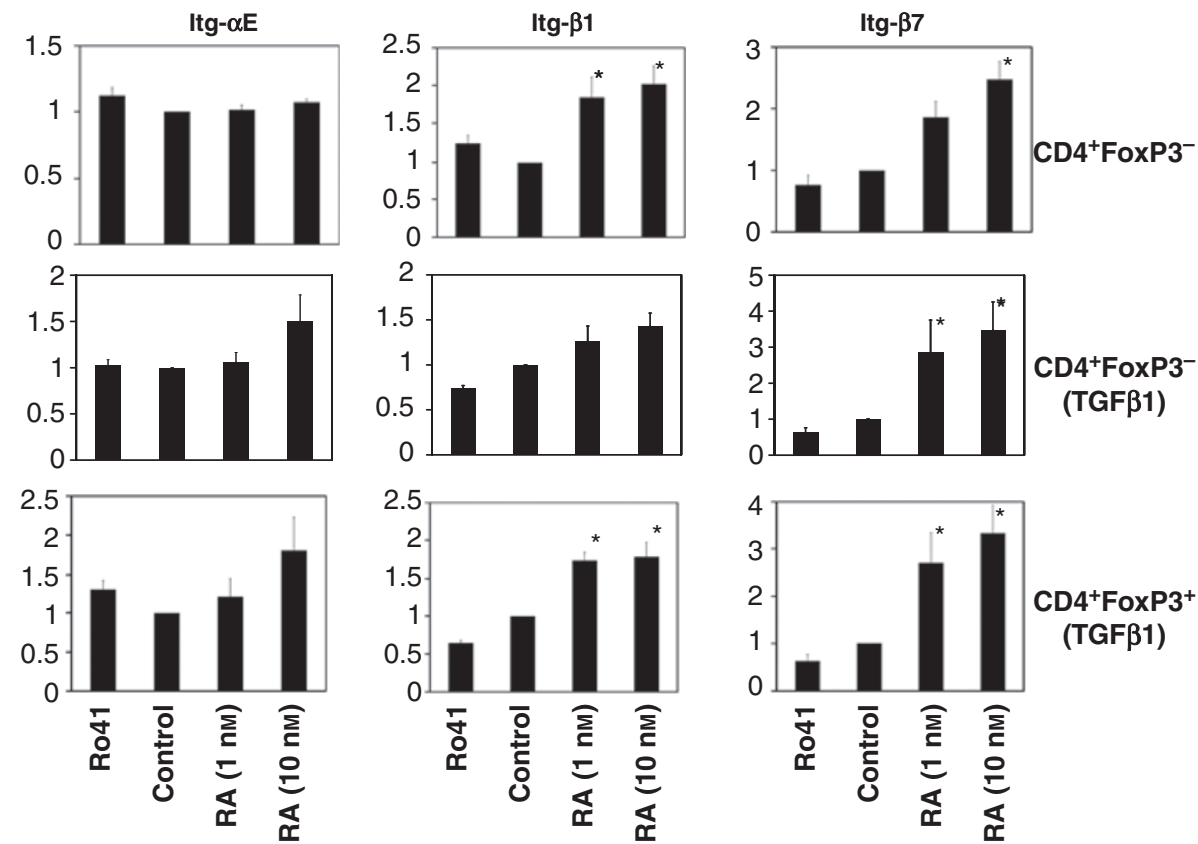

Figure 2 Expression of integrin proteins on the T-cell surface in response to a retinoic acid (RA) gradient. (a) Mouse CD4 ${ }^{+} \mathrm{T}$ cells were activated in the absence or presence of Ro41 or RA for 6 to 7 days and cell surface expression of selected integrins was determined by flow cytometry. Transforming growth factor- $\beta 1$ (TGF $\beta 1 ; 1 \mathrm{ng} \mathrm{ml}^{-1}$ ) was added to indicated cultures to determine any synergistic effects on induced FoxP3 ${ }^{+}$and FoxP3T cells. (b) Expression of Itg- $\alpha_{4}$ and Itg- $\beta_{1}$ by $\alpha_{4} \beta_{7}{ }^{+}$and $\alpha_{4} \beta_{7}{ }^{-}$CD4 ${ }^{+}$T cells treated with RA and/or TGF $\beta 1$. (c) Effects of various retinoic acid receptor- $\alpha$ (RAR) agonists and antagonists on expression of Itg- $\alpha_{4}$, Itg- $\alpha_{E}$, Itg- $\beta_{7}$, and Itg- $\beta_{1}$ by T cells. Expression levels were calculated based on mean fluorescence intensity, which indicates levels of surface antigen expression. Graphs show combined relative expression levels after normalization with the controls $(n=3-6)$. *Significant differences from the controls. 
b
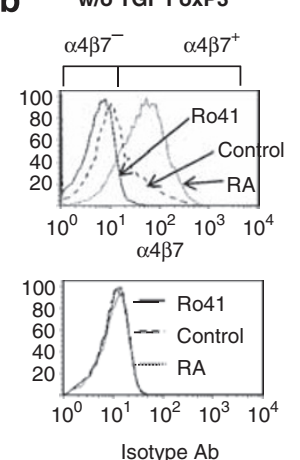

Isotype $\mathrm{Ab}$
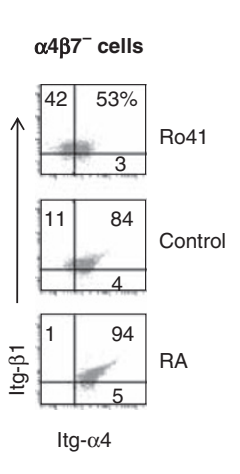
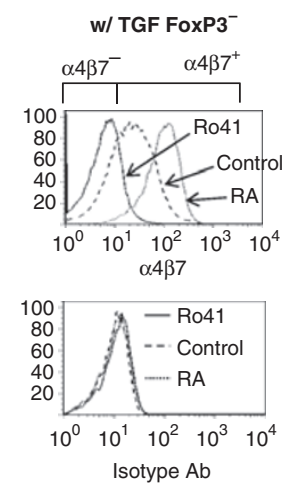

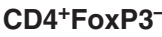

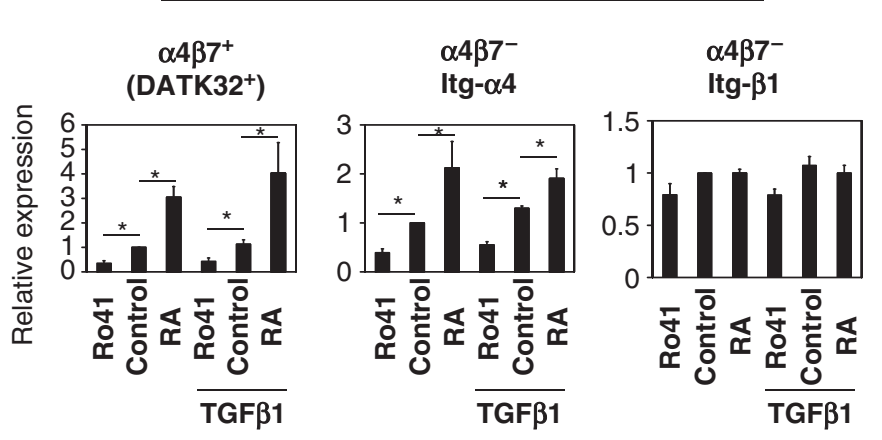

C LE540
(Pan-RAR antagonist)

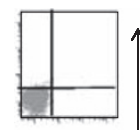
Ro41
(RAR $\alpha$ antagonist)

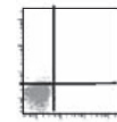

CD2665 (RAR $\beta \gamma$ antagonist)

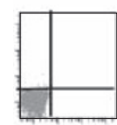

Control

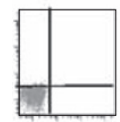

ATRA (Pan-RAR agonist)

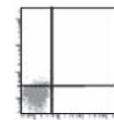
AM580
(RAR $\alpha$ agonist)

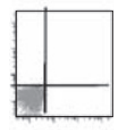

AC55649 (RAR $\beta$ agonist)

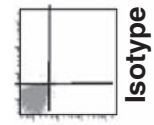

Isotype

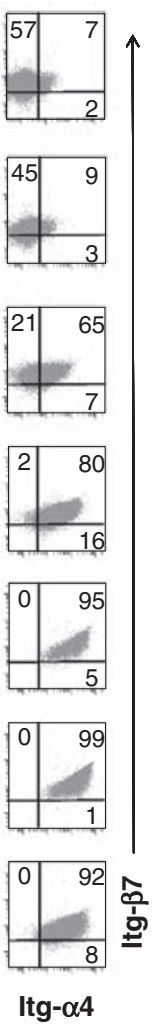

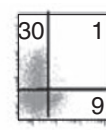
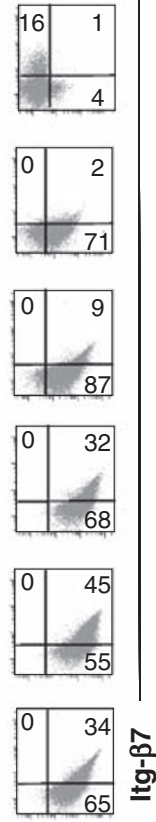

Itg- $\alpha 4$
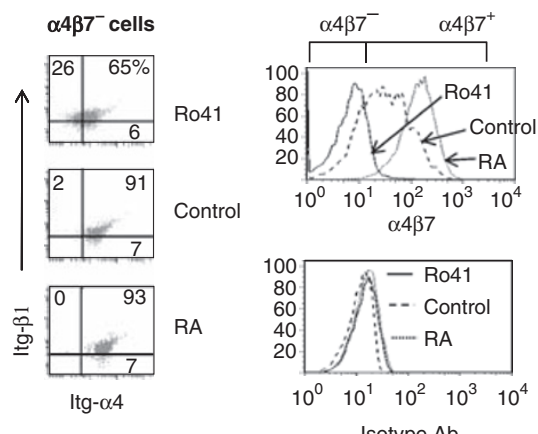

Isotype $\mathrm{Ab}$
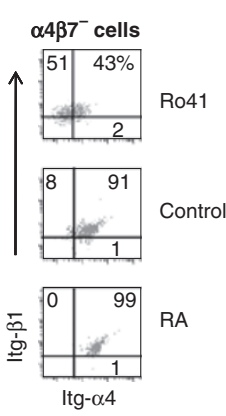

\section{$\mathrm{CD}^{+} \mathrm{FoxP}^{+}$}
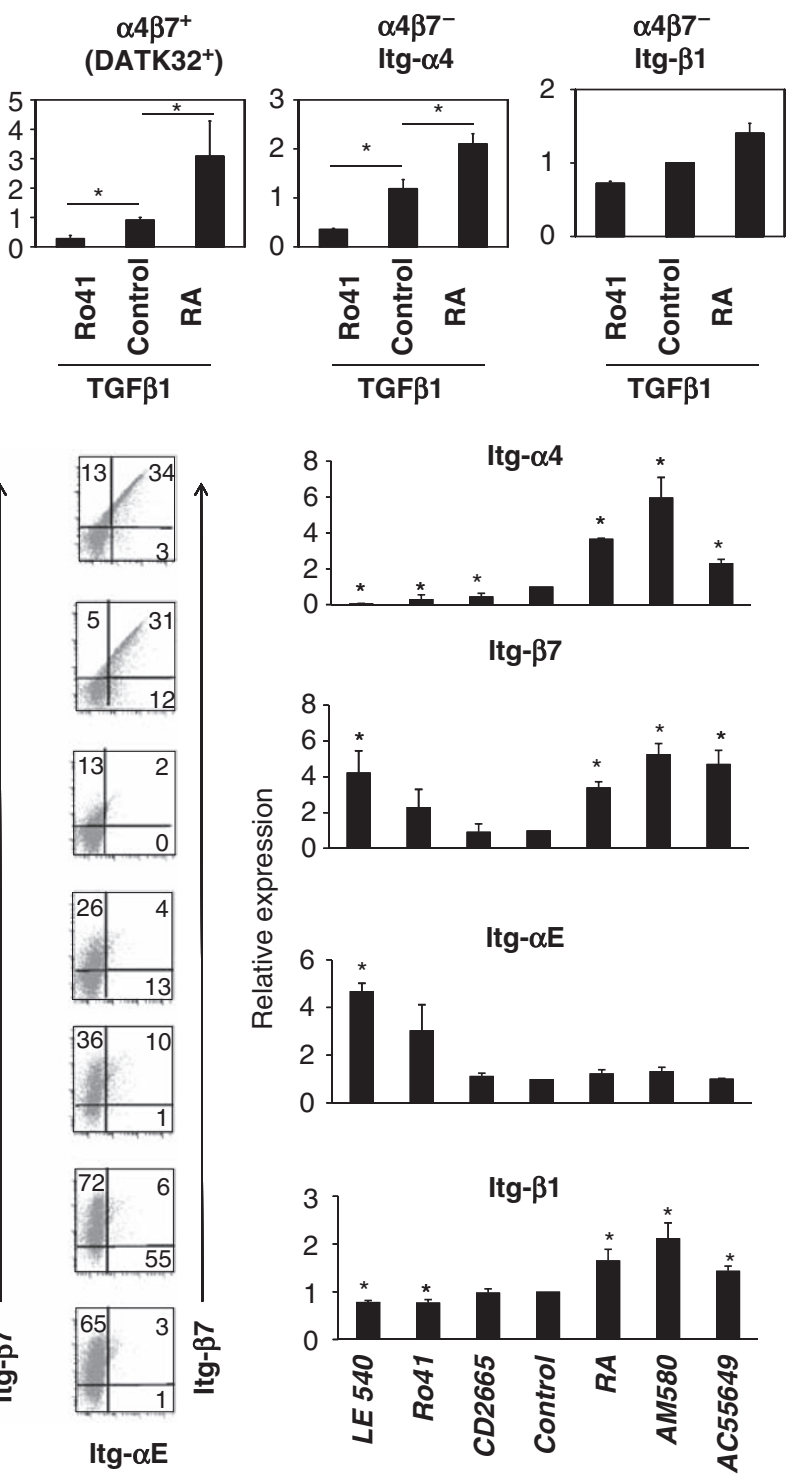

Figure 2 Continued.

medium (Figure 5b). The background expression level of Itg$\alpha_{4}$ and Itg- $\beta_{7}$ was higher in the serum-containing medium compared with the serum-free medium. We also observed that
Itg- $\alpha_{4}$ mRNA expression was increased with the increasing RA signal (Supplementary Figure $S 7$ online). Itg- $\alpha_{E}$ transcription was increased with blocking with Ro41. Itg- $\beta_{7}$ mRNA 
was highly expressed in $\mathrm{CD} 8{ }^{+} \mathrm{T}$ cells in all conditions but was further increased by RA. This response of $\mathrm{CD} 8^{+} \mathrm{T}$ cells to RA is considered a minor difference from the CD $4^{+} \mathrm{T}$ cells.

The effect of RA-dependent Itg- $\alpha_{4}$ expression on T-cell migration $\alpha_{4} \beta_{1}$ binds VCAM- 1 and fibronectin, and $\alpha_{4} \beta_{7}$ binds MadCAM- 1 and VCAM-1. Therefore, deficiency in Itg- $\alpha_{4}$ expression due a
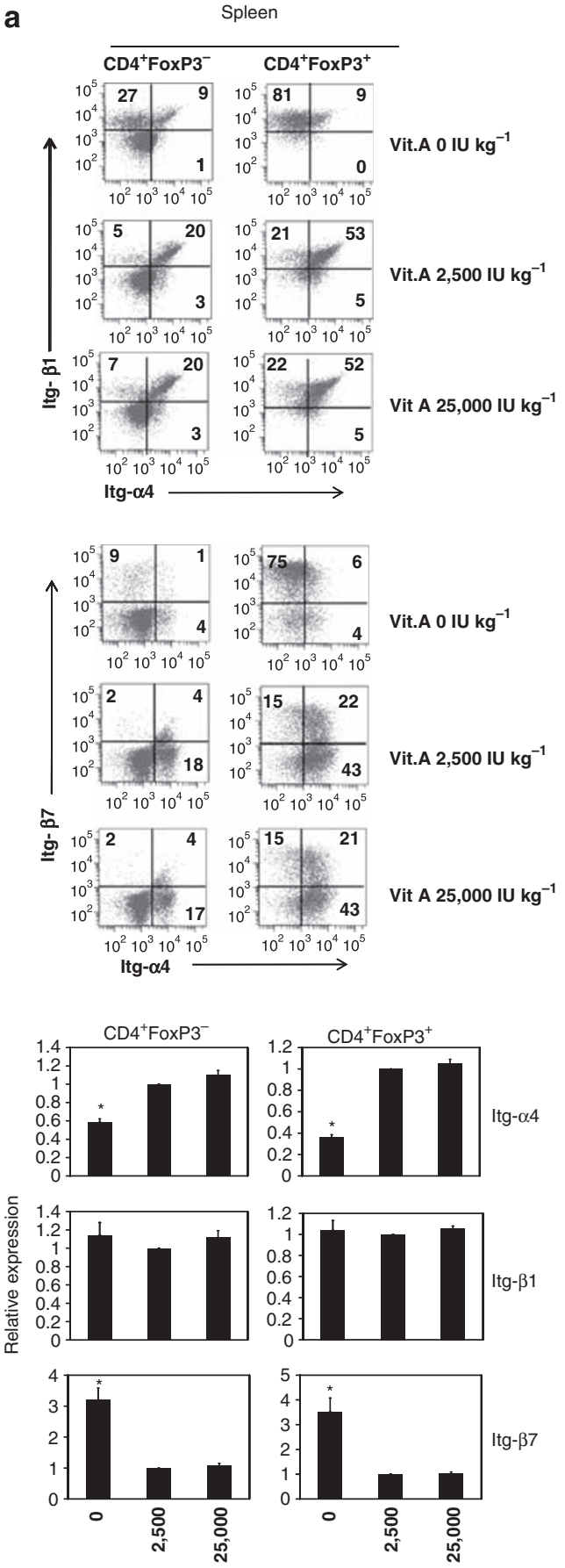

to RAR $\alpha$ blockade would have an important functional consequence on the migration of T cells. We examined whether the T cells with decreased expression of Itg- $\alpha_{4}$ due to RAR $\alpha$ blockade would migrate normally on VCAM-1 in vitro (Figure 6a). The specificity of this migration was confirmed by PS/2 (an Itg- $\alpha 4$ blocking antibody)-dependent blocking of cell migration. Ro41-treated T cells were significantly defective in migration
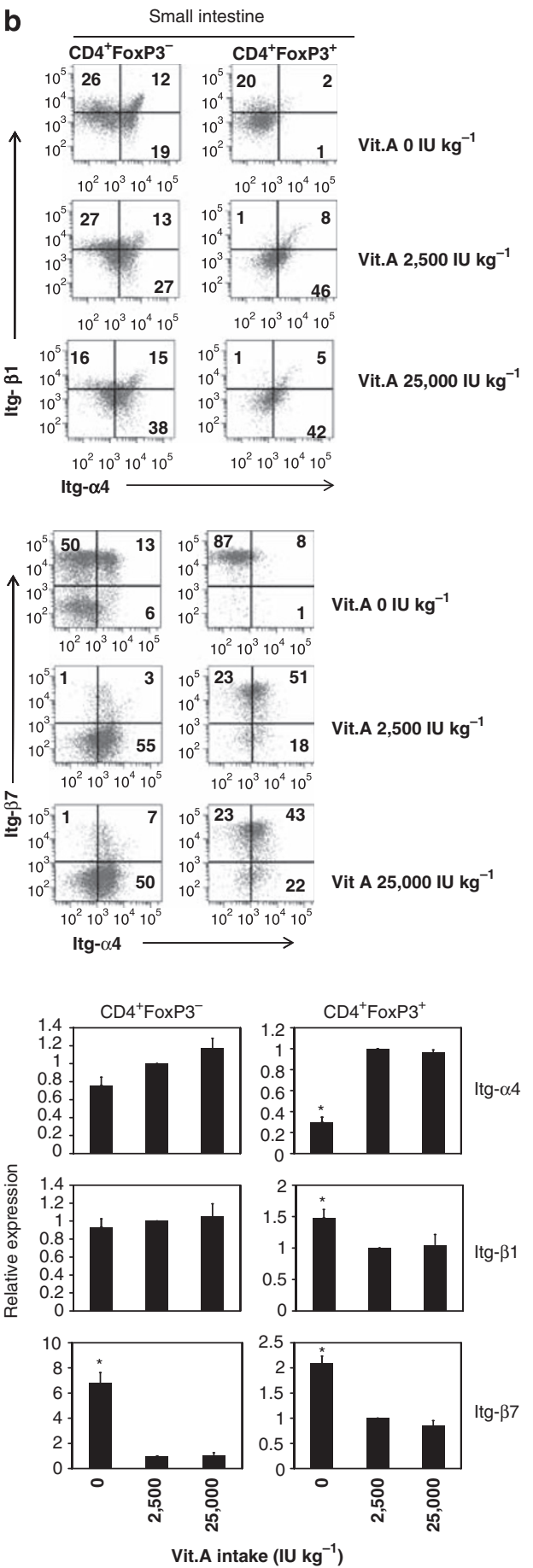

Figure 3 Expression of integrins in vitamin A deficiency. Expression of $\operatorname{ltg}-\alpha_{4}$ and $\operatorname{ltg}-\beta_{7}$ by (a) spleen and (b) small intestinal lamina propria T-cell subsets in vitamin A-deficient, normal, and high mice. Expression of Itg- $\alpha_{E}$ and Itg- $\beta_{7}$ by (c) spleen and (d) small intestinal lamina propria T-cell subsets. Vitamin A-deficient, normal, and high mice were prepared, respectively, by feeding with special diets containing $0,2,500$, and $25,000 \mathrm{IU} \mathrm{kg}^{-1}$ for 12 to 13 weeks after birth. Representative and combined data $(n=4)$ are shown. ${ }^{*}$ Significant differences from the controls $\left(2,500 \mathrm{U} \mathrm{kg}^{-1}\right)$. 
C
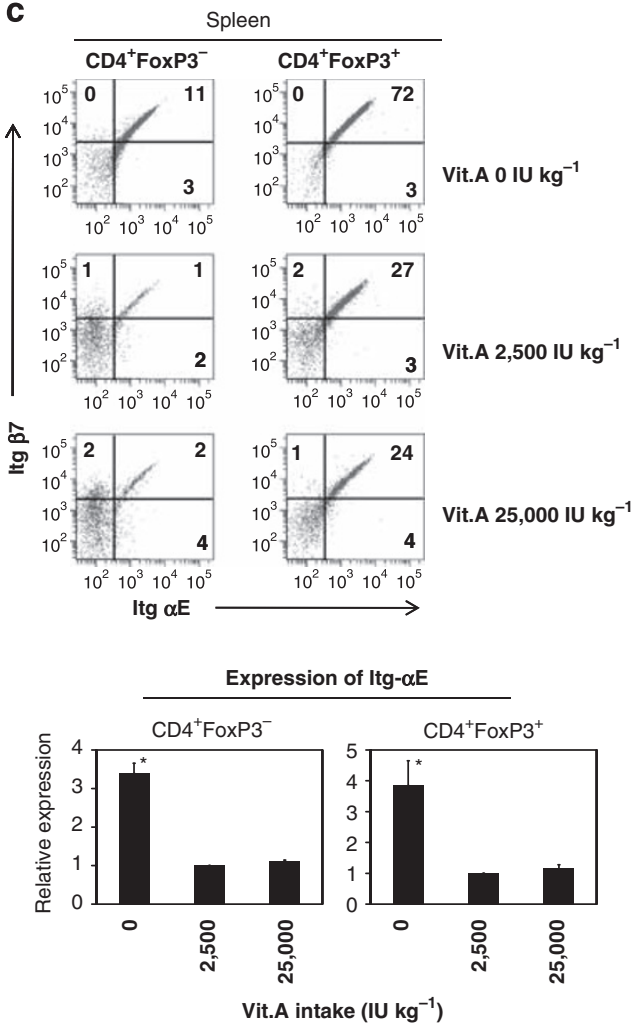

Figure 3 Continued.

through the VCAM-1-coated Transwell membrane. This occurred not only in spontaneous migration but also in stromal cell-derived factor-1/CXCL12-induced chemotaxis (Figure 6a). To determine the effect only on $\alpha 4 \beta 1$, we used $\mathrm{T}$ cells isolated from Itg- $\beta 7$ knockout mice as well. A similar reduction in migration through the VCAM-1-coated Transwell membrane was observed for Ro41-treated T cells (Figure 6b).

We next assessed the in vivo migratory capacity of the Ro41treated T cells compared with RA-treated T cells. Because CCR9, a major trafficking receptor to the small intestine, ${ }^{33-36}$ is another receptor greatly induced by RA, ${ }^{22}$ we used T cells from CCR9deficient mice to rule out the effect of CCR9 on in vivo migration of T cells (Figure 6c, d). We found that Ro41-treated CCR9deficient $\mathrm{T}$ cells were defective in migration to the intestine and Peyer's patches compared with RA-treated CCR9-deficient $\mathrm{T}$ cells (Figure 6c). Their migration to the spleen, mesenteric lymph node, peripheral lymph node, and lung was not affected. Our intravital study revealed that there is a pronounced difference between Ro41-treated T cells and control RA-treated $\mathrm{T}$ cells in adhesion to the endothelium of Peyer's patches (Figure 6e). Thus, the RA-induced expression of Itg- $\alpha_{4}$ is functionally important for T-cell migration in vivo.

\section{DISCUSSION}

Expression of integrins is regulated at several levels of biological processes, including transcription and other post-transcriptional regulatory events, translation in endoplasmic reticulum, dimerization, and transportation from endoplasmic reticulum to the cell surface. ${ }^{37}$ Transcription in response to specific induction signals
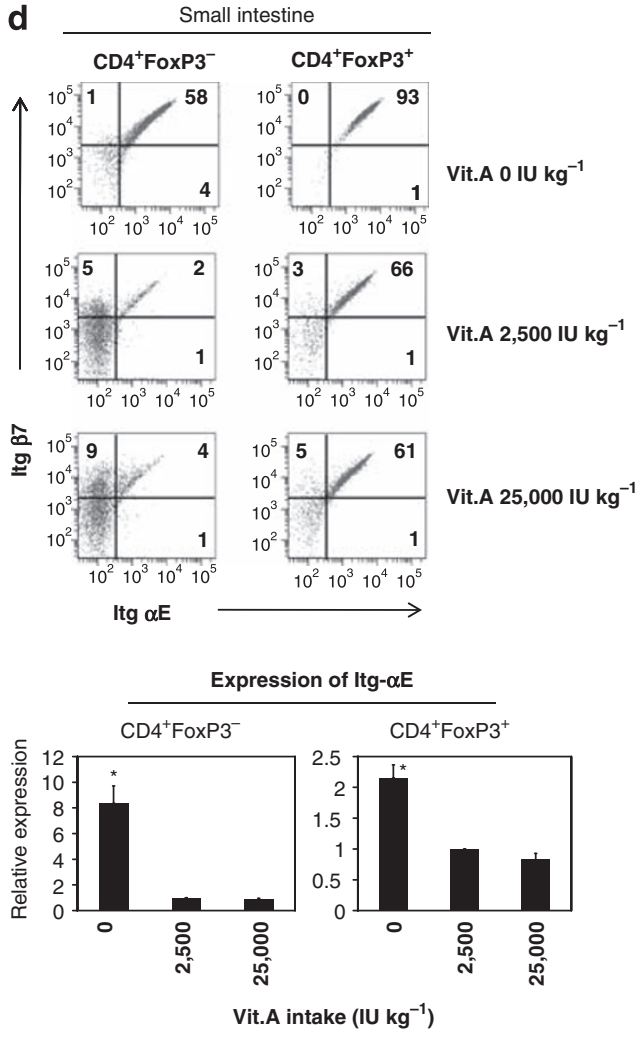

has a central role in the expression of certain integrins. Another important factor for the expression of integrins is availability of heterodimerization partners because monomers cannot be expressed on the cell surface. ${ }^{38,39}$ Availability of dimerization partners is particularly important for the coordinated expression of $\alpha_{4} \beta_{1}$ and $\alpha_{4} \beta_{7}$, which share the common $\alpha 4$ subunit. Similarly, expression of $\alpha_{4} \beta_{7}$ is linked to $\alpha_{E} \beta_{7}$ because of the common $\beta_{7}$ subunit.

We investigated the signals required for the induction of Itg- $\alpha_{4}$ and related integrins. We found that Itg- $\alpha_{4}$ is the integrin that is highly upregulated by RA (Figure 7a). Even at low residual concentrations in a regular medium containing $10 \%$ fetal bovine serum $(\sim 0.5 \mathrm{nM})$, RA is sufficient to induce Itg- $\alpha_{4}$ transcription. This suggests that induction of Itg- $\alpha_{4}$ chain can occur widely in the body at the plasma concentration of RA. This is different from CCR9, which is induced at higher levels $(>5 \mathrm{nM})$ of exogenous RA. This difference in sensitivity to RA would limit the expression of CCR9 to the small-intestinal T cells, whereas $\alpha_{4}$ integrins, particularly $\alpha_{4} \beta_{1}$, is more widely expressed on antigen-primed T cells in most tissues. Because Itg- $\alpha_{4}$ is the common subunit for $\alpha_{4} \beta_{1}$ and $\alpha_{4} \beta_{7}$, RA provides a regulatory signal critical for the expression of the two integrin complexes. On the other hand, RA-vitamin A deficiency induces the expression of $\alpha_{\mathrm{E}} \beta_{7}$ despite the fact that this molecule shares the Itg- $\beta_{7}$ chain with $\alpha_{4} \beta_{7}$. This confirms that RA is not required for transcription of Itg- $\alpha_{\mathrm{E}}$ and Itg- $\beta_{7}$. Indeed, we found that Itg- $\alpha_{\mathrm{E}}$ is mainly upregulated by a different signal provided by TGF $\beta 1$. Itg- $\beta_{7}$ is constitutively expressed and can be further induced by TGF $\beta 1$. We did not examine the roles of TGF $\beta$ isoforms other than TGF $\beta 1$ in integrin regulation. In support of our findings, it was previously reported that transcription of Itg- $\alpha_{\mathrm{E}}$ and Itg- $\beta_{7}$ in a CD8 ${ }^{+}$leukemic T cell line (TK-1) can be increased 
by TGF $\beta 1 .^{31}$ Whether TGF $\beta 1$ induces the expression of Itg- $\alpha_{\mathrm{E}}$ and Itg- $\beta_{7}$ in primary naive $\mathrm{CD} 4^{+} \mathrm{T}$ cells during antigen priming has not been determined despite the fact that natural and TGF $\beta 1$-induced FoxP3 ${ }^{+}$T cells highly express $\alpha_{\mathrm{E}} \beta_{7}{ }^{17,41}$

Although both Itg- $\beta_{7}$ and Itg- $\beta_{1}$ are upregulated on the surface of $\mathrm{T}$ cells in response to RA, RA seems to have no essential role in transcription of these molecules. The increased expression of $\alpha_{4} \beta_{1}$ and $\alpha_{4} \beta_{7}$ in response to RA is largely because of increased transcription and expression of Itg- $\alpha_{4}$. Although we observed a certain increase of Itg- $\beta_{7}$ transcription in CD8 T cells in response to RA, this induction seems to be not important for $\alpha_{4} \beta_{7}$ expression, as Itg- $\beta_{7}$ is not a limiting factor. Thus, increased availability of Itg- $\alpha_{4}$ leads to increased assembly of integrin complexes formed between pre-existing Itg- $\beta_{1}$ or Itg- $\beta_{7}$ chains and the RA-induced Itg- $\alpha_{4}$ chain. This is supported by a recent publication by Shimizu group ${ }^{40}$ that levels of Itg- $\beta_{1}$ expression can negatively a

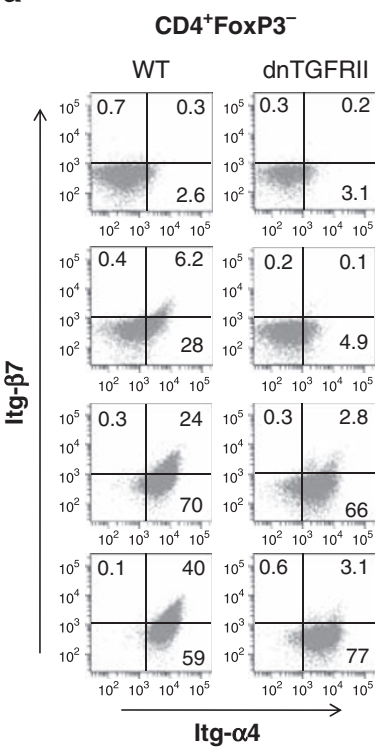

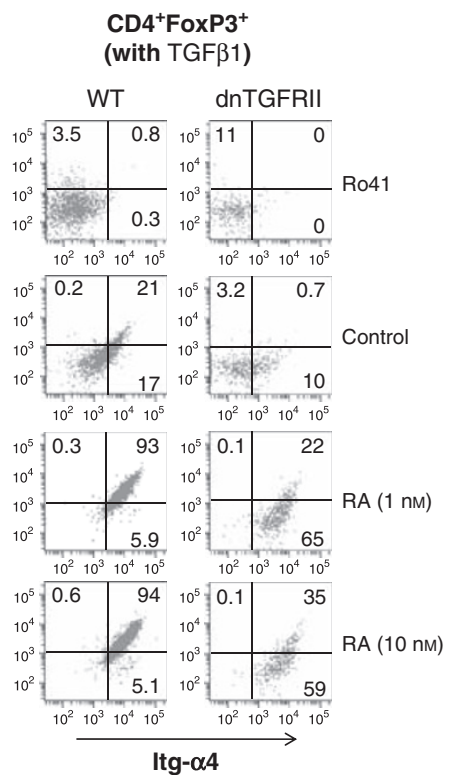
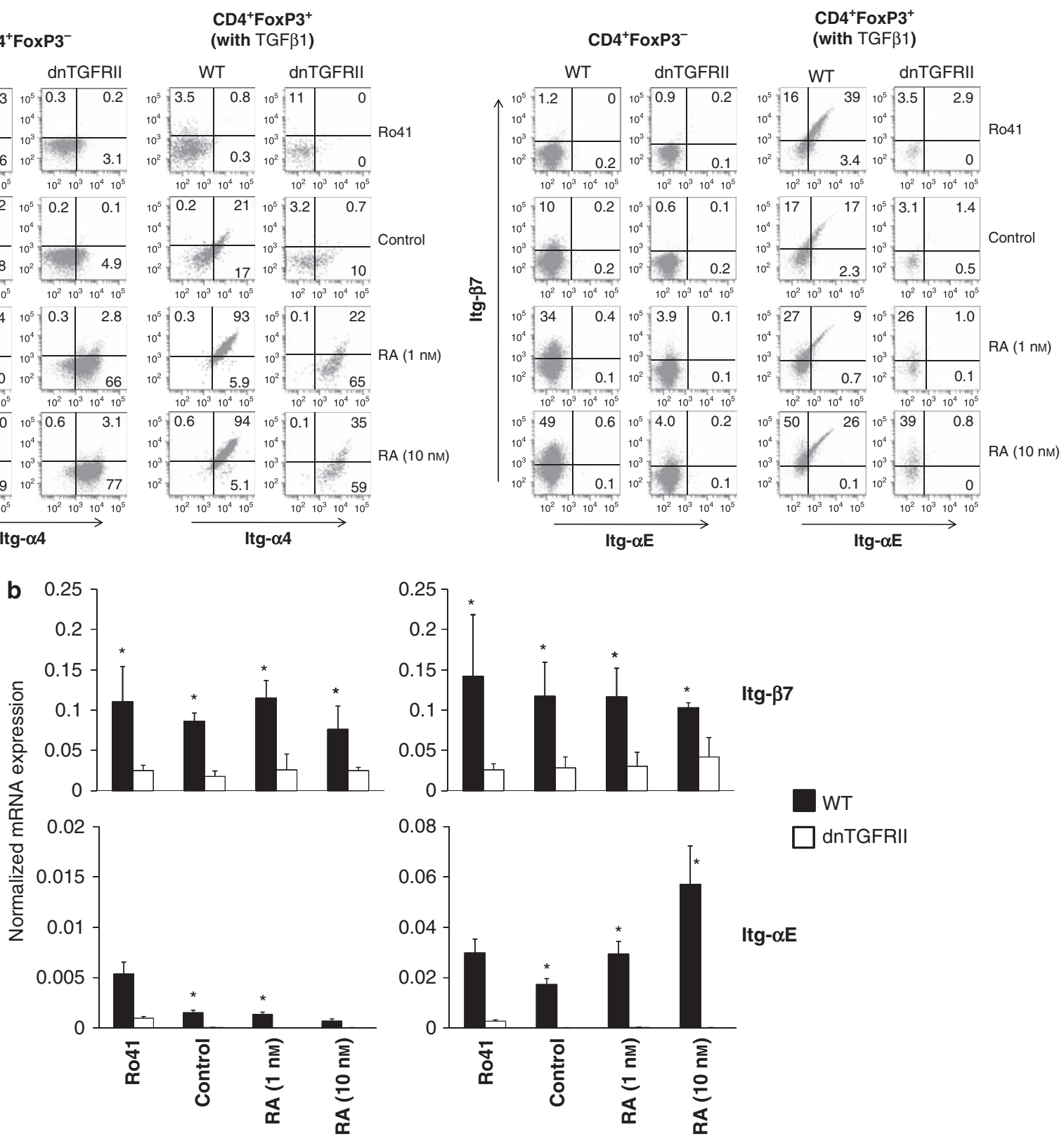

$\operatorname{ltg}-\alpha E$

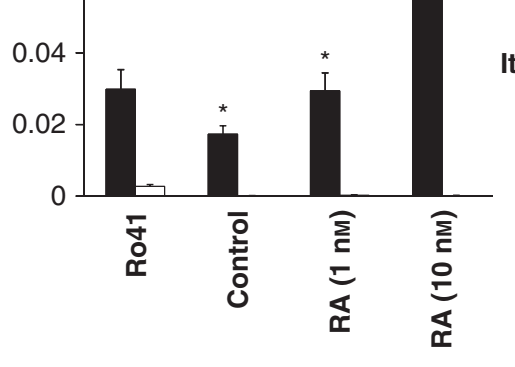

TGF $\beta 1\left(1 \mathrm{ng} \mathrm{ml}^{-1}\right)$

Figure 4 Transforming growth factor- $\beta 1$ (TGF $\beta 1$ ) signal is required for expression of Itg- $\beta_{7}$ and Itg- $\alpha_{E}$. (a) Surface expression of $\alpha_{4} \beta_{7}$ and $\alpha_{E} \beta_{7}$ in the presence and absence of TGF $\beta$ signal. A retinoic acid (RA) gradient is made with Ro41, RA (1 nM), and RA (10 nM) in $10 \%$ fetal bovine serum (FBS)-containing medium. TGF $\beta 1\left(1 \mathrm{ng} \mathrm{ml}^{-1}\right)$ was added to indicated cultures. Naive CD4 ${ }^{+} \mathrm{T}$ cells, isolated from wild-type or dnTGF $\beta$ RII mice, were cultured for 6 to 7 days in the different RA-TGF $\beta$ conditions. Representative data $(n=4)$ are shown. (b) Expression of indicated Itg genes at the mRNA level is shown. Combined real-time PCR data with s.e.m. of three independent experiments is shown. (c) Expression of Itg- $\alpha_{E}$ and Itg- $\beta_{7}$ by the T cells in dnTGF $\beta$ RII mice. (d) Expression of Itg- $\alpha_{4}$ and Itg- $\beta_{1}$ by the T cells in dnTGF $\beta$ RII mice. The graphs show combined data (percentage of positive cells among each T-cell subset) obtained from three different mice per group. 


\section{ARTICLES}

C

Spleen

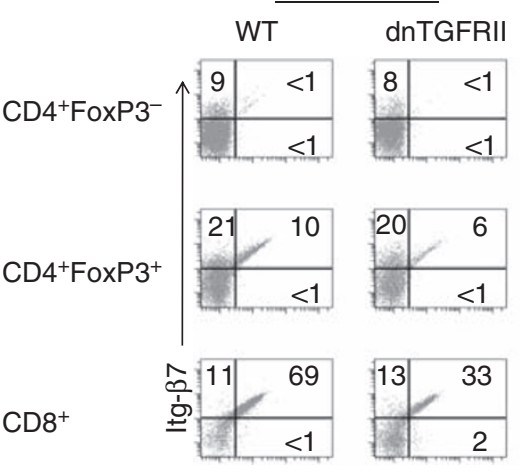

Small intestine

WT dnTGFRII

Large intestine
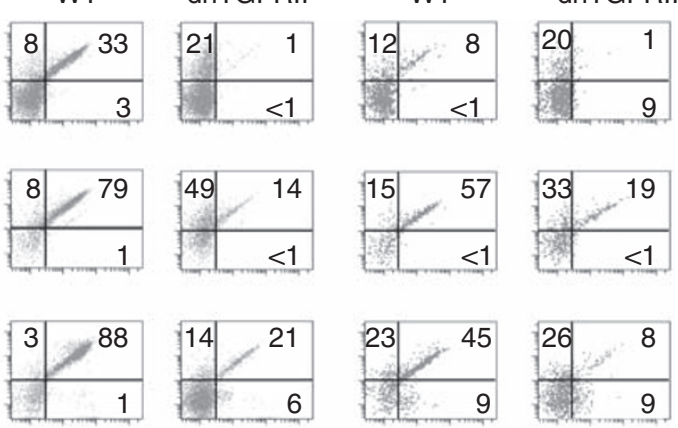

Itg- $\alpha \mathrm{E}$
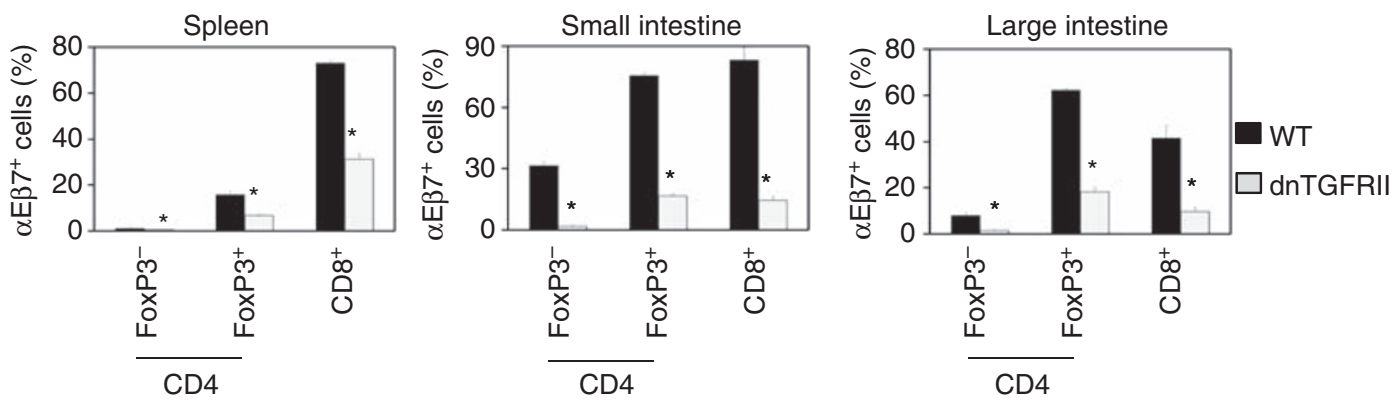

d

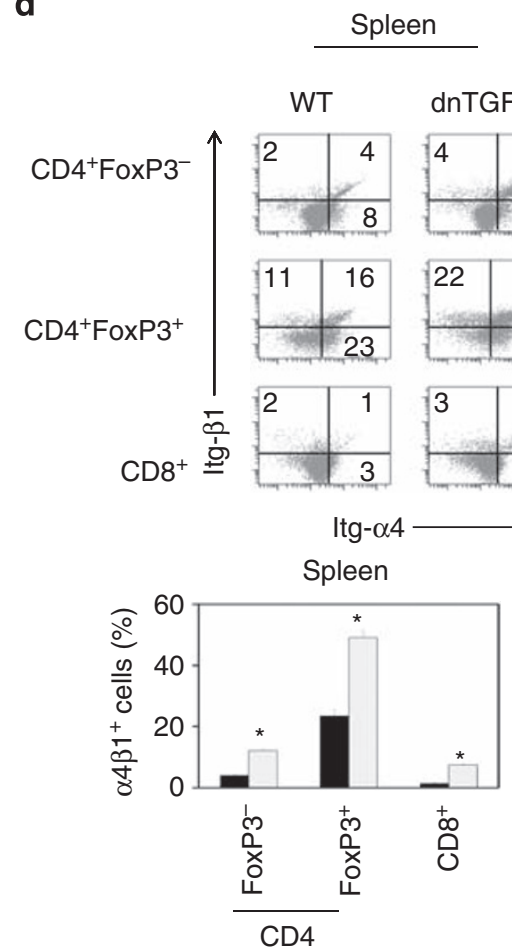

Small intestine

Large intestine
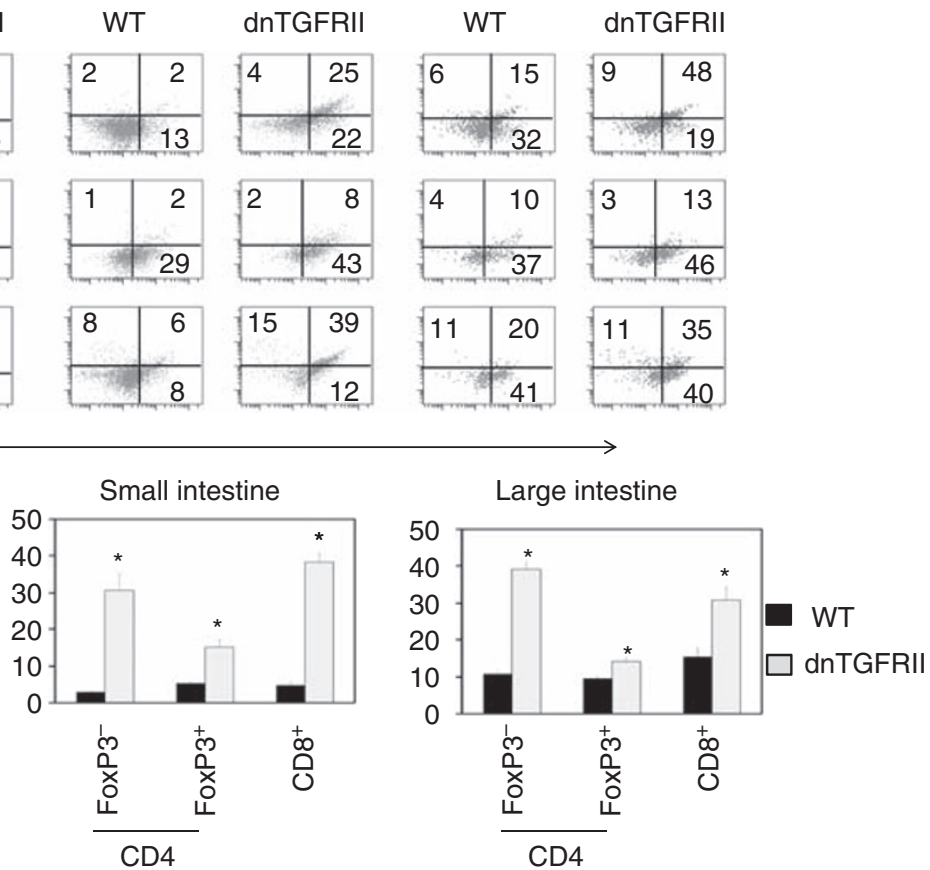

Figure 4 Continued.

affect $\alpha_{4} \beta_{7}$ expression through competition for Itg- $\alpha_{4}$ molecules available for dimerization. Reciprocally, we found that decreased expression of Itg- $\beta_{7}$, as observed in T cells of CD4-dnT $\beta$ RII mice, can lead to increased expression of $\alpha_{4} \beta_{1}$. In addition, we need to consider that there are many additional $\beta_{1}$ integrins besides $\alpha_{4} \beta_{1}$, which could further affect the regulation of the integrins. Thus, competition between Itg- $\beta$ subunits is an important factor in the surface expression of $\alpha_{4}$ integrins (Figure $7 \mathbf{b}$ ). 
a CD8 T cells in $10 \%$ FBS
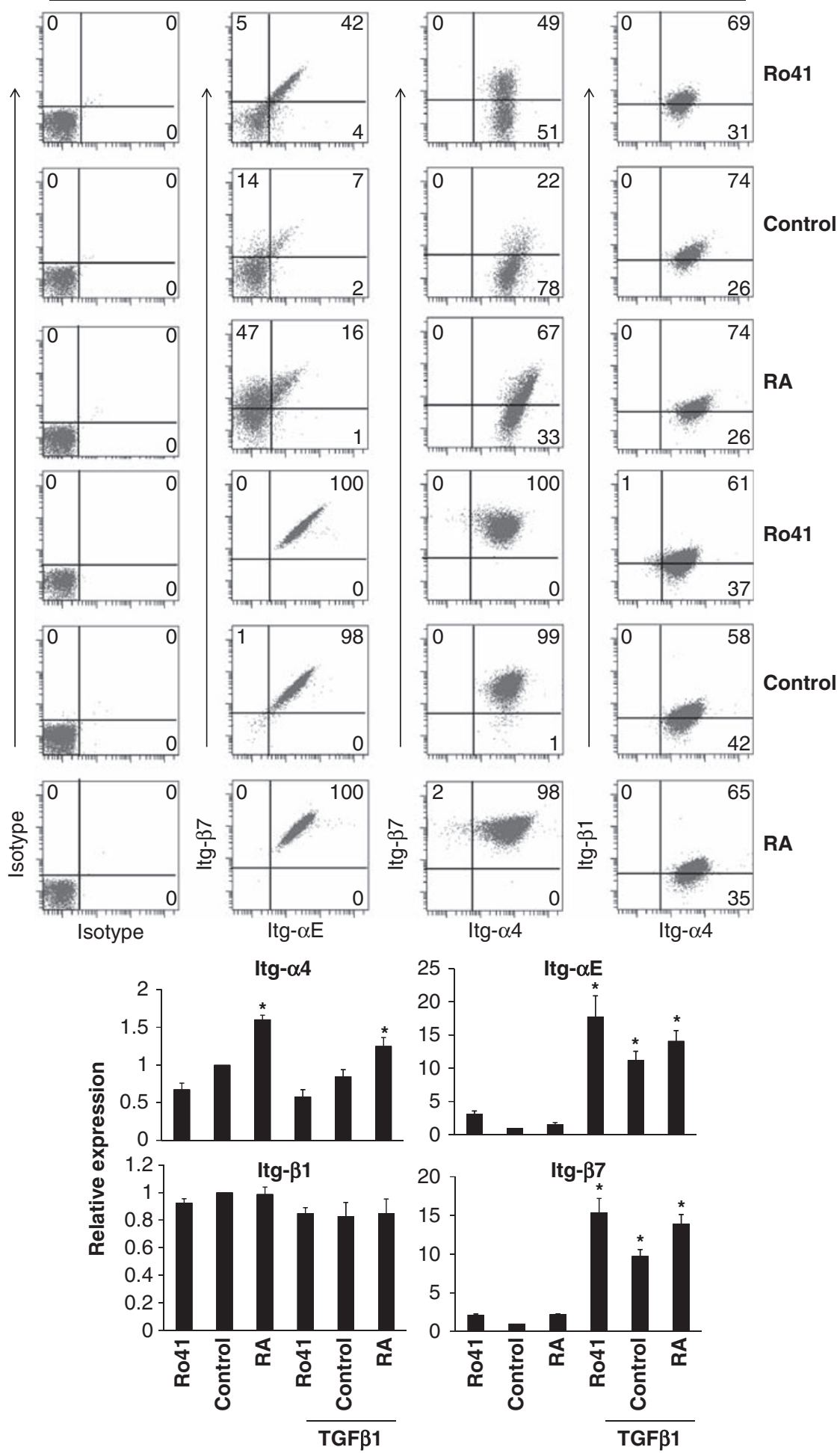

Figure 5 Regulation of integrins on $\mathrm{CD}^{+} \mathrm{T}$ cells by retinoic acid (RA) and transforming growth factor- $\beta 1$ (TGF $\beta 1$ ). Mouse CD8 ${ }^{+} \mathrm{T}$ cells were activated in the absence or presence of Ro41 or RA for 5 to 6 days in (a) a 10\% fetal bovine serum (FBS)-containing medium or (b) a serum-free medium, and cell surface expression of selected integrins was determined by flow cytometry. The small subset of CD8 ${ }^{+}$FoxP3 ${ }^{+} \mathrm{T}_{\text {cells }}$ were excluded from the analysis. TGF $\beta 1\left(1 \mathrm{ng} \mathrm{ml}^{-1}\right)$ was added to indicated cultures to determine any synergistic effects. Graphs show combined relative expression levels after normalization for controls $(n=3)$. *Significant differences from the controls.

The surface expression of the Itg- $\beta_{7}$ chain was greatly increased in response to RAR blockade or in vitamin A deficiency, because its pairing partner, the Itg- $\alpha_{\mathrm{E}}$ subunit, is greatly induced in this condition in a manner dependent on the TGF $\beta 1$ signal. This upregulation of $\alpha_{\mathrm{E}} \beta_{7}$ in RA deficiency is probably because of increased availability of Itg- $\beta_{7}$ molecules for pairing with Itg- $\alpha_{\mathrm{E}}$ when Itg- $\alpha_{4}$ expression 

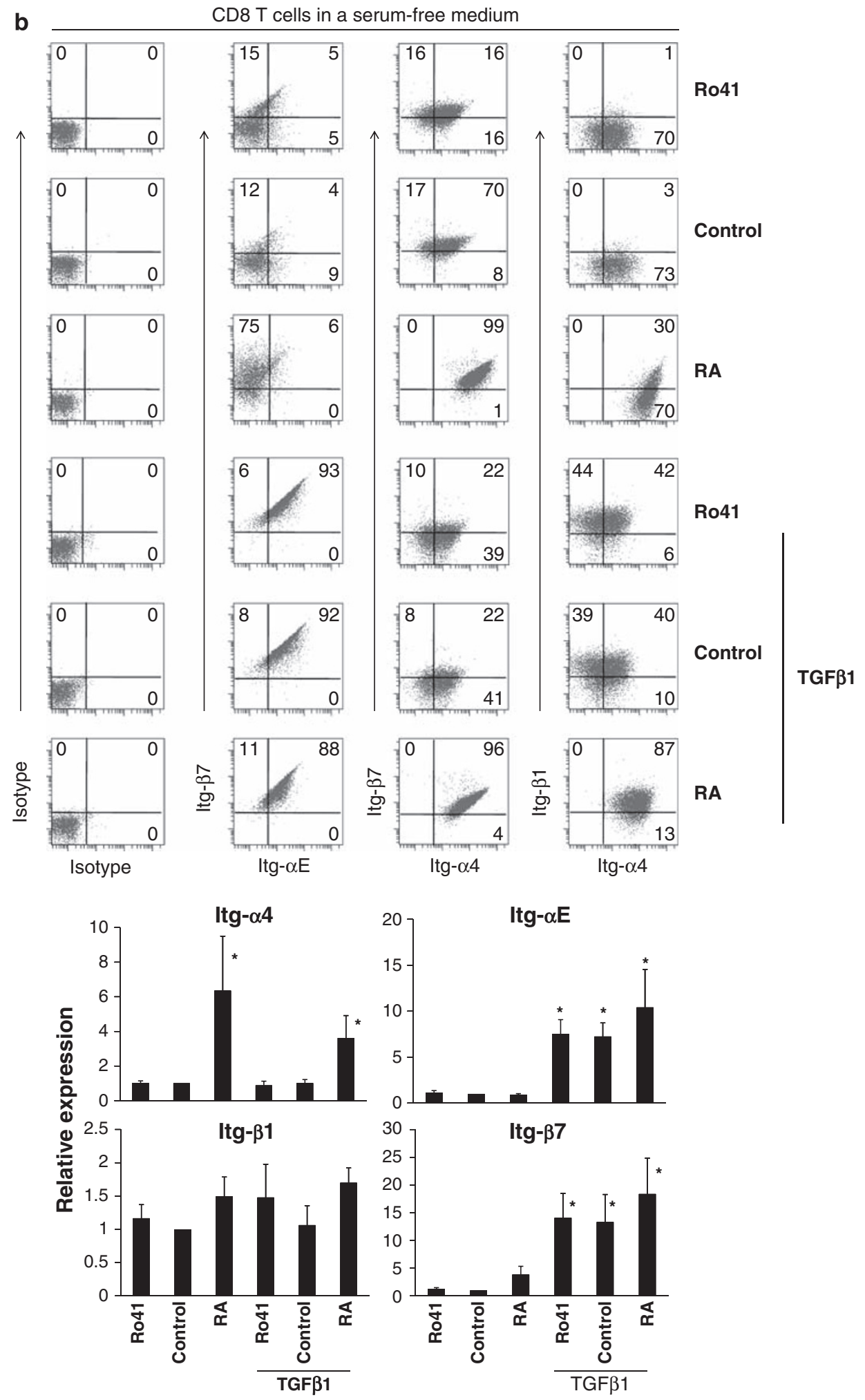

Figure 5 Continued.

is severely decreased (Figure 7b). Another mechanism is active induction of Itg- $\alpha_{\mathrm{E}}$ transcription in RA deficiency.

The two integrins $\alpha_{4} \beta_{1}$ and $\alpha_{4} \beta_{7}$ have critical roles in lymphocyte migration for both homeostatic and inflammatory purposes. Normal expression of $\alpha_{4} \beta_{1}$ and $\alpha_{4} \beta_{7}$ is required for mounting effective immunity and inducing chronic inflammation. Moreover, Itg- $\alpha_{4}$ is an effective target for treatment of inflammatory diseases. ${ }^{42,43} \mathrm{~A}$ side effect of blocking Itg$\alpha_{4}$ is increased susceptibility to infection. ${ }^{44,45}$ Our results show that $\alpha_{4} \beta_{1}$ and $\alpha_{4} \beta_{7}$ integrins are greatly decreased on 
a

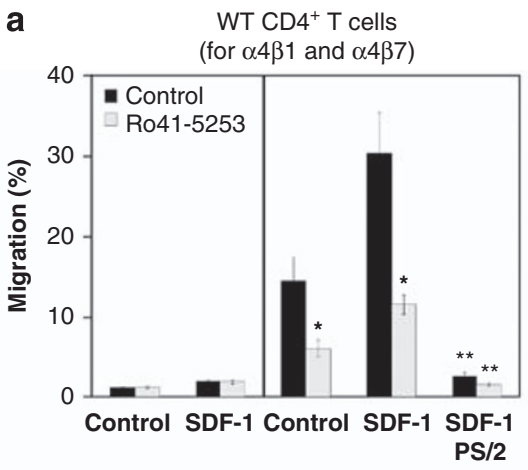

on VCAM1 b

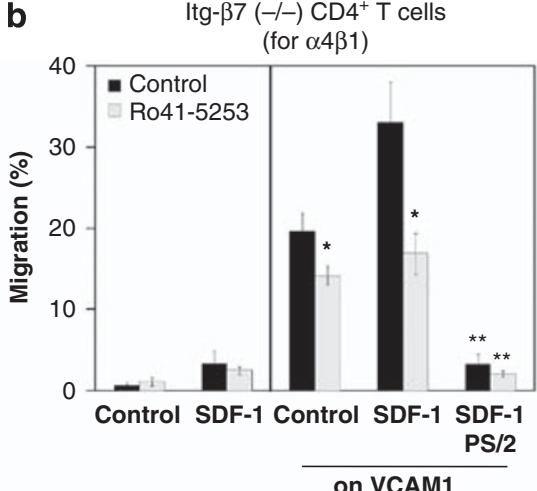

c
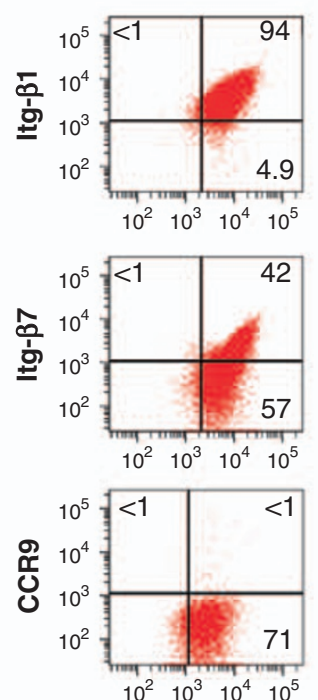

Itg- $\alpha 4$

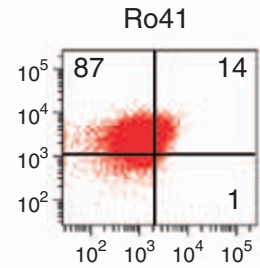

\section{d RA vs. Ro41 treated}

d

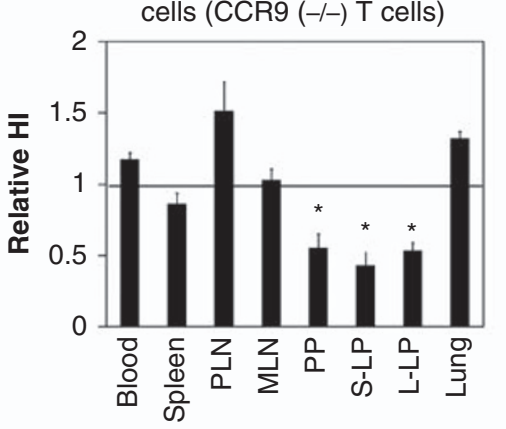

e
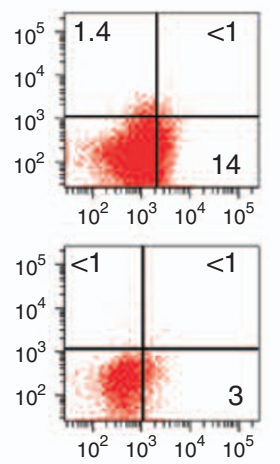

Itg- $\alpha 4$

- RA-treated CCR9 (-I-) T cells • Ro41-treated CCR9 (-l-) T cells
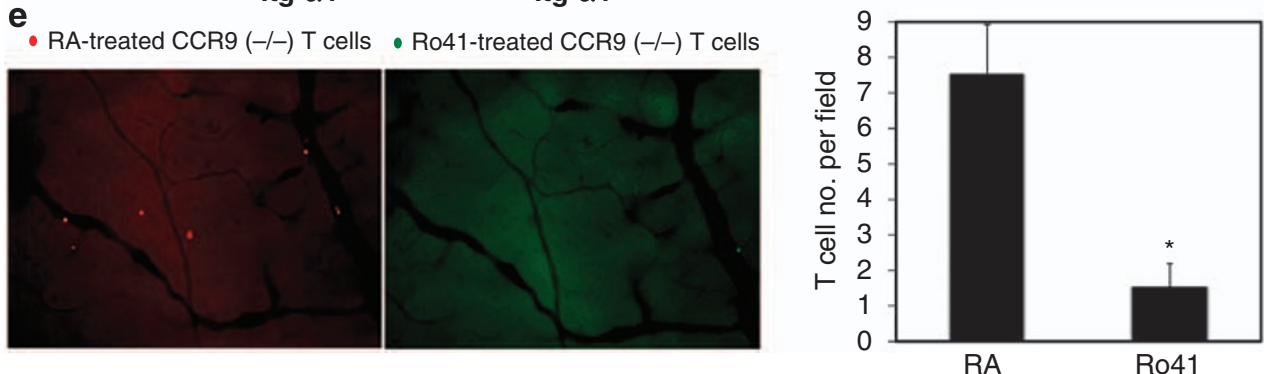

Figure 6 Functional effects of Itg- $\alpha_{4}$, induced by low concentrations of retinoic acid (RA), on migration of T cells in vitro and in vivo. (a, b) Migration of Itg- $\alpha_{4}$-low and normal T cells through vascular cell adhesion molecule 1 (VCAM1)-coated Transwells in response to stromal cell-derived factor-1 (SDF-1) or control medium was examined. Wild-type T cells can express both $\alpha_{4} \beta_{1}$ and $\alpha_{4} \beta_{7}$, whereas $\operatorname{ltg} \beta_{7}(-/-)$ T cells express $\alpha_{4} \beta_{1}$ but not $\alpha_{4} \beta_{7}$. Combined data of three independent experiments are shown. Naive CD4 ${ }^{+}$T cells, isolated from (a) wild-type or (b) Itg $\beta 7(-/-)$ mice were cultured in the presence of control medium or Ro41 to prepare control and Itg $\alpha_{4}$-low T cells, respectively. PS/2, an Itg- $\alpha_{4}$ blocking monoclonal antibody, was used to block the Itg- $\alpha_{4}$-dependent migration. ${ }^{*}$ Significant differences from control T cells. ${ }^{\star \star}$ Significant differences from the SDF-1 groups. (c) Surface phenotype of $\mathrm{CD} 4^{+} \mathrm{T}$ cells used for the in vivo homing study. Chemokine (C-C motif) receptor 9 (CCR9; $-/-$ ) naive CD4 ${ }^{+} \mathrm{T}$ cells were cultured in the presence of RA or Ro41 to prepare control and Itg- $\alpha_{4}$-low T cells. CCR9 (-/-) naive CD4 ${ }^{+} \mathrm{T}$ cells were used to exclude the effect of CCR9 (another trafficking receptor induced by RA) on migration. (d) Migration of Itg- $\alpha_{4}$-low T cells in vivo. A 20 -h short-term in vivo homing assay to various organs including the peripheral lymph node (PLN), mesenteric lymph node (MLN), Peyer's patches (PP), small intestinal lamina propria (S-LP), and large intestinal lamina propria (L-LP) was performed. Homing indices $<1$ indicate decreased homing compared with control T cells. Combined data $(n=4-6)$. (e) Intravital microscopy was performed to visualize the migrating Itg- $\alpha_{4}$-low and control CCR9 $(-/-)$ T cells to Peyer's patches immediately after the T-cell transfer. A representative set of data of three independent experiments is shown. Error bars indicate s.d. of the number of cells per field (number of cells rolling, arrested, and migrated) in Peyer's patches in 20 image frames. * Significant decreases in migration. 


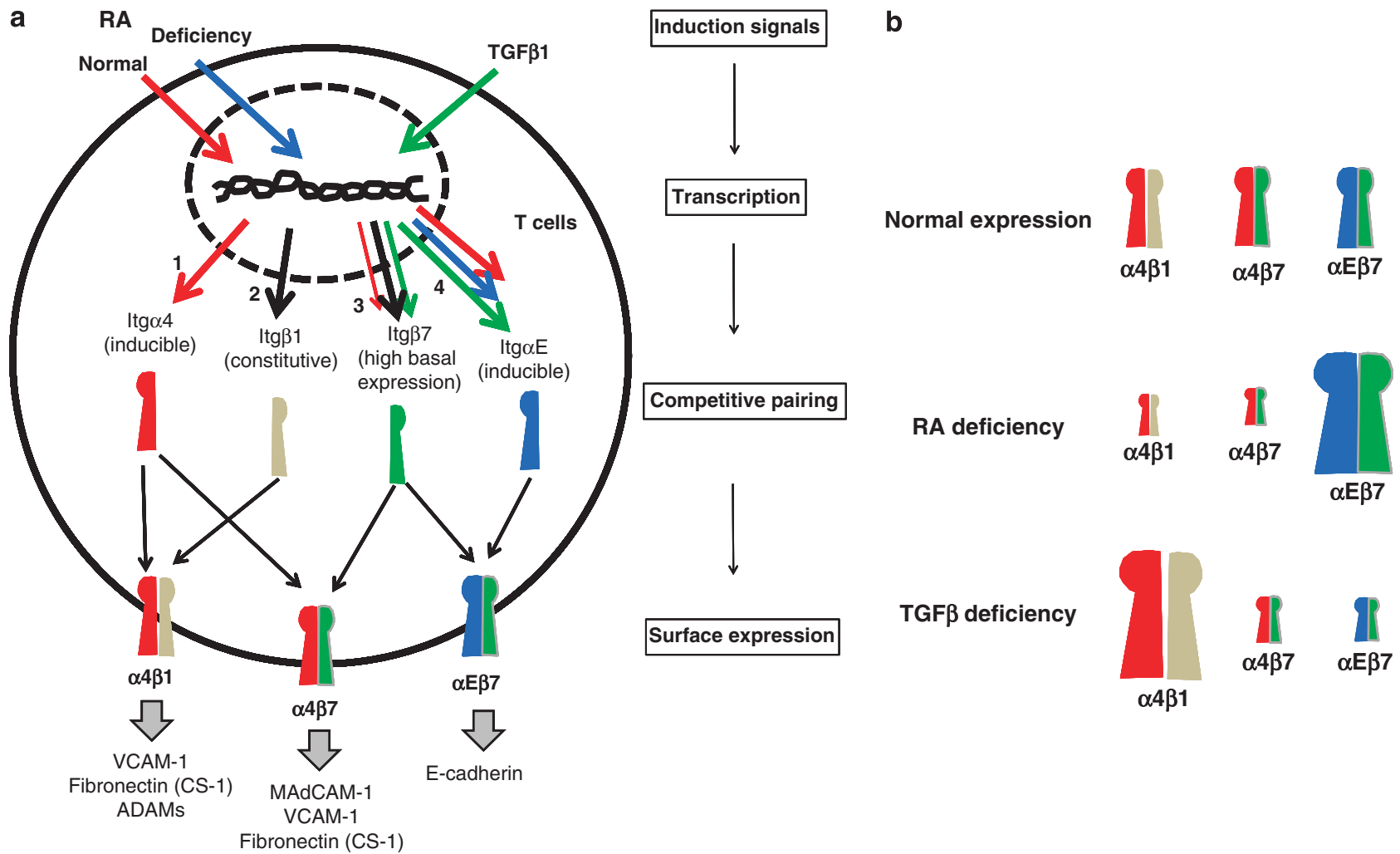

Figure 7 Coordinated regulation of the expression of $\alpha_{4} \beta_{1}, \alpha_{4} \beta_{7}$, and $\alpha_{E} \beta_{7}$ by retinoic acid (RA) and transforming growth factor- $\beta 1$ (TGF $\beta 1$ ) in T cells. (a) RA positively induces Itg- $\alpha_{4}$ (red lines) but RA paucity induces Itg- $\alpha_{E}$ (blue lines). In contrast, Itg- $\alpha_{E}$ is induced by TGF $\beta 1$ (green lines), whereas Itg- $\beta_{1}$ is constitutively expressed by activated T cells. Itg- $\beta_{7}$ is constitutively expressed but can be further induced by TGF $\beta 1$. In addition, RA seems to increase Itg- $\beta_{7}$ expression in CD8 ${ }^{+} T$ cells. Because of the heterodimerization requirement, expression of the three integrins is influenced by RA and TGF $\beta$ signals in combination. $\alpha_{4} \beta_{1}$ can be induced by RA alone, whereas high expression of $\alpha_{4} \beta_{7}$ requires both RA and TGF $\beta 1$. High expression of $\alpha_{E} \beta_{7}$ requires TGF $\beta 1$. In the intestine and other tissues, in which RA is available at optimal concentrations, high expression of $\alpha_{4} \beta_{1}$ and $\alpha_{4} \beta_{7}$ by T cells occurs. (b) In vitamin A deficiency, decreases in expression of $\alpha_{4} \beta_{1}$ and $\alpha_{4} \beta_{7}$ but increases in $\alpha_{E} \beta_{7}$ occur because of decreased Itg- $\alpha_{4}$ and increased ltg- $\alpha_{E}$ expression. In a TGF $\beta$ signal deficiency, $\alpha_{4} \beta_{1}$ is overexpressed because the expression of $\alpha_{4} \beta_{7}$ (and $\alpha_{E} \beta_{7}$ ) is suppressed, freeing up Itg- $\alpha_{4}$ molecules for pairing with Itg- $\beta_{1}$. Reciprocally, $\alpha_{4} \beta_{7}$ is overexpressed when $\alpha_{4} \beta_{1}$ is not expressed because of Itg- $\beta_{1}$ deficiency. ${ }^{40}$ This regulatory mechanism operates in most $\mathrm{T}$ cells, including FoxP3 ${ }^{+}, \mathrm{CD}_{4}^{+}$, and $\mathrm{CD}^{+} \mathrm{T}$ cells. The size of integrins in the diagram signifies the amount of expression.

the surface of T cells in vitamin A deficiency. Decreased expression of these integrins leads to defective migration to various mucosal tissues such as the lung and intestine. It is likely that the increased susceptibility to infection in vitamin A-deficient individuals is, in part, because of the decreased expression of the $\alpha_{4}$ integrins and consequentially lowered effector functions of immune cells. ${ }^{46}$

The changes in expression levels of $\alpha_{4} \beta_{1}, \alpha_{4} \beta_{7}$, and $\alpha_{\mathrm{E}} \beta_{7}$ in different retinoid-vitamin A status occur in all of the T-cell subsets examined in this study such as $\mathrm{CD} 4{ }^{+} \mathrm{T}$ cells and $\mathrm{CD} 8^{+} \mathrm{T}$ cells. It is particularly notable that expression of the integrins by RA and TGF $\beta 1$ is more clearly regulated in FoxP3 ${ }^{+} \mathrm{T}$ cells. We believe that this is, in part, because of the fact that TGF $\beta 1$ is required for induction of both FoxP3 and integrins (i.e., Itg- $\alpha_{\mathrm{E}}$ and Itg- $\beta_{7}$ ). Therefore, the RA- and TGF $\beta$-dependent regulation of the integrins would have profound effects on migration and function of FoxP3 ${ }^{+}$T cells as well. Defective migration of FoxP3 ${ }^{+}$ $\mathrm{T}$ cells can promote inflammatory diseases and explains, in part, the increased inflammation in vitamin A deficiency. ${ }^{47}$

\section{METHODS}

Cell isolation and culture. $\mathrm{CD} 4^{+} \mathrm{T}$ cells were isolated from pooled single-cell suspensions of spleen, mesenteric lymph nodes, and peripheral lymph node with the $\mathrm{CD} 4^{+} \mathrm{T}$-cell isolation kit (Miltenyi Biotec, Auburn, CA). Cells expressing CD8, CD19, CD25, CD44, and CD69 were further depleted to obtain naive $\mathrm{CD} 4^{+} \mathrm{T}$ cells (purity of $\sim 95 \%$ ). Total $\mathrm{CD} 8^{+} \mathrm{T}$ cells were isolated using the $\mathrm{CD} 8^{+} \mathrm{T}$-cell isolation kit (Miltenyi Biotec), and were further depleted for CD4, CD19, CD25, CD44, and CD69 cells to obtain naive $\left(\mathrm{CD} 8^{+} \mathrm{CD} 25^{-} \mathrm{CD} 44^{-} \mathrm{CD} 69^{-}\right) \mathrm{CD} 8^{+} \mathrm{T}$ cells (purity of $\sim 93 \%$ ). Naive cells were activated for 5 to 6 days with complete RPMI1640 medium containing concanavalin $\mathrm{A}\left(2.5 \mu \mathrm{g} \mathrm{ml}^{-1}\right)$ and human interleukin-2 $\left(100 \mathrm{U} \mathrm{ml}^{-1}\right)$ in the presence or absence of one of the agonists or antagonists: RA ( = At-RA; 1 or $10 \mathrm{~nm}$ from Sigma Aldrich, St Louis, MO), Ro41-5253 (hereafter called Ro41, 500 nM, purchased from Biomol, Farmingdale, NY), LE540 (500 nM, pan-RAR antagonist; Wako Chemical, Richmond, VA), CD2665 (500 nm, selective RAR- $\beta / \gamma$ antagonist; Tocris Bioscience, Ellisville, MO), AM580 (20 nM, RAR $\alpha$ agonist; Tocris), and AC55649 (100 nm, RAR $\beta 2$ agonist; Tocris). Optimal concentrations of these reagents were determined by a preliminary titration study. Human TGF $\beta 1\left(1 \mathrm{ng} \mathrm{ml}^{-1}\right)$ was used when indicated. For the experiment in Supplementary Figure $\mathbf{S}$ online, cycloheximide $\left(10 \mu \mathrm{g} \mathrm{ml}^{-1}\right.$; Enzo, Farmingdale, NY) was used. The T cells were also cultured in a serum-free 
medium (HL-1 from Lonza, Allendale, NJ) for 5 to 6 days with the T-cell activation-Expansion kit (anti-CD3 and CD28 beads: $6 \mu$ per million cells; Miltenyi Biotec) and human interleukin-2 $\left(100 \mathrm{U} / \mathrm{ml}^{-1}\right)$ in the presence of RA (10 nM), Ro41 (100 nM), and/or TGF $\beta 1\left(1 \mathrm{ng} \mathrm{ml}^{-1}\right)$.

Animals and generation of vitamin A-deficient or sufficient mice. All the experiments with animals in this study were approved by the Purdue animal care and use committee. CCR9-deficient mice were described previously. ${ }^{48} \operatorname{Itg}-\beta_{7}(-/-)$ mice (C57BL/6-Itgb $7^{\mathrm{tm} 1 \mathrm{Cgn} / \mathrm{J})}$ and dominant form of TGFRII transgenic mice (B6.Cg- Tg $(\mathrm{Cd} 4-$ TGFBR2)16Flv/J) were purchased from the Jackson Laboratory (Bar Harbor, ME). For generation of mice with excessive, normal, or deficient vitamin A status, BALB/c mice (Jackson Laboratory) were kept on custom diets based on AIN-93G containing high $\left(25,000 \mathrm{IU} \mathrm{kg}^{-1}\right.$; tenfold higher than the normal dietary range), normal $\left(2,500 \mathrm{IU} \mathrm{kg}^{-1}\right)$, or low $\left(0 \mathrm{IU} \mathrm{kg}^{-1}\right)$ (Harlon Teklad, Indianapolis, IN: TD-06528, 00158, and 07267 ) levels of vitamin A as previously described. ${ }^{49}$ The pups were weaned at 4 weeks of age and maintained on the same diets for additional 9 weeks. Vitamin A deficiency was verified by defective CCR9 expression by small intestinal $\mathrm{T}$ cells as described previously. ${ }^{49}$

Flow cytometry. Itg- $\alpha_{4}$ was stained sequentially with purified antimCD49d antibody (clone 9C10; BioLegend) followed by biotin anti-rat IgG2a (clone MRG2a-83; BioLegend) and Streptavidin-PerCP/Cy5.5 (BioLegend, San Diego, CA). To detect expression of Itg- $\beta_{1}, \beta_{7}$, and $\alpha_{\mathrm{E}}$ respectively, antibodies to $\mathrm{mCD} 29$ (clone HMß1-1), mItg- $\beta_{7}$ (clone FIB504), and mCD103 (clone 2E7) were used. Anti-mLPAM-1 (DATK32) was used to detect $\alpha_{4} \beta_{7}$. When indicated, cells were stained for intracellular mFoxP3 with an antibody (clone FJK-16s; eBioscience, San Diego, CA). Stained cells were analyzed using a BD Canto II (BD Bioscience, San Diego, CA).

Homing experiment. Wild-type or CCR9-deficient T cells were prepared by culturing with RA or Ro41 and labeled with carboxyfluorescein diacetate succinimidyl ester (CFSE) or tetramethylrhodamine isothiocyanate (TRITC). The two cell types ( 5 million cells for each cell type per mouse) were co-injected through a tail vein into C57BL/6 mice. After $20 \mathrm{~h}$, the mice were killed and single-cell suspensions were prepared from selected organs after collagenase digestion as previously described.$^{50}$ The numbers of the injected $\mathrm{CFSE}^{+}$or TRITC ${ }^{+}$cells present in each organ was determined with flow cytometry. The relative homing index was determined according to the formula: homing index for organ $\mathrm{A}=\left(\right.$ no. of TRITC ${ }^{+}$ cells in organ $\mathrm{A}) /\left(\right.$ no. of $\mathrm{CFSE}^{+}$cells in $\left.\operatorname{organ} \mathrm{A}\right) \div\left(\right.$ no. of TRITC $^{+}$cells in input)/(no. of $\mathrm{CFSE}^{+}$cells in input).

VCAM-1-dependent chemotaxis. Chemotaxis was performed with Transwells ( $3.0 \mu \mathrm{m}$ pores; Corning, Corning, NY). The Transwells were coated with mouse VCAM-1 (100 $\mu \mathrm{g} \mathrm{ml}^{-1}$; R\&D Systems, Minneapolis, $\mathrm{MN})$ in $50 \mu \mathrm{l}$ of $\mathrm{NaHCO}_{3}(0.1 \mathrm{M}, \mathrm{pH} 8.0)$ by incubating overnight at $4^{\circ} \mathrm{C}$, and blocked with $2 \%$ bovine serum albumin for $30 \mathrm{~min}$ at room temperature. RA- (CFSE-labeled) and Ro41 (TRITC-labeled)-treated T cells $\left(0.5 \times 10^{5}\right.$ cells each) in $100 \mu$ l of chemotaxis buffer (RPMI-1640, $0.5 \%$ bovine serum albumin) were loaded onto the upper chamber. Stromal cell-derived factor- $1 \alpha\left(100 \mathrm{ng} \mathrm{ml}^{-1}, \mathrm{R} \& \mathrm{D}\right.$ Systems) was added to the lower chamber. Neutralizing anti-mItg- $\alpha 4$ monoclonal antibody (PS/2, $5 \mu \mathrm{g} \mathrm{ml}^{-1}$ ) was added to block the cells in the upper chamber when indicated. The cells were allowed to migrate for $4 \mathrm{~h}$ at $37^{\circ} \mathrm{C}$, and the cells that migrated to the lower chamber were counted with flow cytometry.

Intravital microscopy to monitor T-cell migration into gut lymphoid tissues. CCR9-deficient T cells, cultured with RA or Ro41 and labeled with CFSE or TRITC, were injected through a tail vein into C57BL/6 mice. Immediately after the injection of the labeled cell into anesthetized mice, Peyer's patches were exposed and observed in a custom-designed intravital device equipped with a Leica (Bannockburn, IL) DMI 3000B fluorescent microscope and a dynamic ultra low light fluorescence camera
(Retiga-EXi; QImaging, Surrey, BC, Canada). The images were acquired every $0.5 \mathrm{~s}$ in sequence with the QCapture Pro6.0 software (Surrey, BC, Canada). Images were analyzed frame by frame for the presence of cells adhering to the endothelium, which include the cells under both rolling and sticking. Data from at least 30 images were averaged to obtain numbers of cells adhering to the Peyer's patch endothelium.

Microarray and data analysis. RNA, isolated from cultured CD4 ${ }^{+} \mathrm{T}$ cells, was hybridized to Mouse 4302.0 chips (Affymetrix, Santa Clara, CA) by the Purdue Genomics Laboratory staff. These arrays contain over 39,000 complementary DNA spots corresponding to mouse sequence verified transcripts. Raw intensity values were obtained (GeneChip Operating Software, Affymetrix) and normalized with the expression values of a housekeeping gene ( $\beta$ actin). Selection and filtering of high-quality genes was based on a twofold or greater differential in expression up or down between two conditions of comparison. Further selection was based on reproducibility between duplicated experiments, and transcripts without consistent results were dismissed. The gene expression values were visualized with the multiplot module of the GenePattern genomic analysis platform (www.broad.mit.edu/cancer/ software/genepattern). The raw and processed array data have been deposited at http://www.ncbi.nlm.nih.gov/geo/query/acc.cgi?acc=GSE20500.

Chromatin immunoprecipitation assay. The chromatin immunoprecipitation assay was performed using a kit following the manufacturer's instruction (Upstate Biotechnology, Lake Placid, NY). In brief, $2 \times 10^{6}$ naive $\mathrm{CD} 4^{+} \mathrm{T}$ cells were cultured in the presence or absence of RA $(10 \mathrm{nM})$ or Ro41 (500 nM). Concanavalin A $\left(2.5 \mu \mathrm{g} \mathrm{ml}^{-1}\right)$ and human interleukin-2 $\left(25 \mathrm{U} \mathrm{ml}^{-1}\right)$ were used to activate T cells. The cells were cultured for 4 to 5 days, fixed in paraformaldehyde, and made into cell lysates. The chromosomal DNA-protein complex was sonicated to generate DNA fragments with their size ranging from 200 to $1000 \mathrm{bp}$. DNA-protein complexes were immunoprecipitated using $4 \mu \mathrm{g}$ of polyclonal antibody against mouse RAR $\alpha$ (Santa Cruz Biotech, Santa Cruz, CA). Genomic DNA enriched with antibodies against RAR $\alpha$ was uncross-linked and analyzed by PCR for detection of RAREs in the mouse Itg- $\alpha_{4}$ gene promoter with the following primer pairs: $5^{\prime}$-TACTTTGATGTCTATTTCTCTGG$3^{\prime}$ and 5'-GGATAGCAAGAAGTGCTGTCC-3' (RARE1); $5^{\prime}$-AAGCCATCAGTGCTTCTCACC-3' and 5' -GGAGAGACC TTGTGTCAAAGAA-3' (RARE2); $5^{\prime}$-ATTCAGCTTGGCTGACAGGGA-3' and $5^{\prime}$-TCC TTTTGCCTCTGCCTGCC-3' (RARE3); 5' -TCCTATAA GCTTTGTTTTCAGCC- ${ }^{\prime}$ and 5' $^{\prime}$-ACAACGTTTTATCTCATAA GTAATC-3' (RARE4/5); 5' -AAAACTACCCATCTACTATAAAC AA- $3^{\prime}$ and $5^{\prime}$-CAACTCAAACTCCTATTAAGTTCT-3' (RARE6); $5^{\prime}$-TCTGAACCTAGCAACTGCCAC- ${ }^{\prime}$ and $5^{\prime}$-CCACTCCCAG TCTTTTGGAGA-3' (RARE7). Real-time PCR detection was performed with a 7500 Sequence Detection System (Applied Biosystems, Foster City, CA) using the SYBR green Master Mix (Applied Biosystems).

Statistical analyses. Student's paired and unpaired $t$-tests were used to compare the significance of the differences between two groups of related or unrelated data. The $P$-values of $\leqslant 0.05$ were considered significant.

SUPPLEMENTARY MATERIAL is linked to the online version of the paper at http://www.nature.com/mi

\section{ACKNOWLEDGMENTS}

We thank J.S. Chang, J.H. Lee, and C.W. Wang (Purdue University) for their helpful inputs and A. Feil for her excellent service with microarray hybridization and scanning (Purdue Genomics Core Facility). This study was supported, in part, by grants from NIH (1R01AI074745, 1R56AI080769, and 1R01DK076616) and Crohn's and Colitis Foundation of America to C.H.K.

\section{DISCLOSURE}

The authors declared no conflict of interest.

C 2011 Society for Mucosal Immunology 


\section{REFERENCES}

1. Linker, R.A., Kieseier, B.C. \& Gold, R. Identification and development of new therapeutics for multiple sclerosis. Trends Pharmacol. Sci. 29, 558-565 (2008)

2. Rutgeerts, P., Vermeire, S. \& Van Assche, G. Biological therapies for inflammatory bowel diseases. Gastroenterology 136, 1182-1197 (2009).

3. Morimoto, C., Iwata, S. \& Tachibana, K. VLA-4-mediated signaling. Curr. Top. Microbiol. Immunol. 231, 1-22 (1998).

4. Wardlaw, A.J., Symon, F.S. \& Walsh, G.M. Eosinophil adhesion in allergic inflammation. J. Allergy Clin. Immunol. 94, 1163-1171 (1994).

5. Andrew, D.P., Rott, L.S., Kilshaw, P.J. \& Butcher, E.C. Distribution of alpha 4 beta 7 and alpha $E$ beta 7 integrins on thymocytes, intestinal epithelial lymphocytes and peripheral lymphocytes. Eur. J. Immunol. 26, 897-905 (1996).

6. Fanjul, A.N. et al. 4-Hydroxyphenyl retinamide is a highly selective activator of retinoid receptors. J. Biol. Chem. 271, $22441-22446$ (1996).

7. Pribila, J.T., Quale, A.C., Mueller, K.L. \& Shimizu, Y. Integrins and T cell-mediated immunity. Annu. Rev. Immunol. 22, 157-180 (2004).

8. Alon, R. et al. The integrin VLA-4 supports tethering and rolling in flow on VCAM-1. J. Cell. Biol. 128, 1243-1253 (1995).

9. Berlin, C. et al. alpha 4 integrins mediate lymphocyte attachment and rolling under physiologic flow. Cell 80, 413-422 (1995).

10. von Andrian, U.H. \& Engelhardt, B. Alpha4 integrins as therapeutic targets in autoimmune disease. N. Engl. J. Med. 348, 68-72 (2003).

11. Vermeulen, M. et al. Role of adhesion molecules in the homing and mobilization of murine hematopoietic stem and progenitor cells. Blood 92 894-900 (1998).

12. Sigmundsdottir, H. \& Butcher, E.C. Environmental cues, dendritic cells and the programming of tissue-selective lymphocyte trafficking. Nat. Immunol. 9, 981-987 (2008).

13. Hamann, A., Andrew, D.P., Jablonski-Westrich, D., Holzmann, B. \& Butcher, E.C. Role of alpha 4-integrins in lymphocyte homing to mucosal tissues in vivo. J. Immunol. 152, 3282-3293 (1994).

14. Wolber, F.M. et al. Endothelial selectins and alpha4 integrins regulate independent pathways of $\mathrm{T}$ lymphocyte recruitment in the pulmonary immune response. J. Immunol. 161, 4396-4403 (1998).

15. Cepek, K.L. et al. Adhesion between epithelial cells and T lymphocytes mediated by E-cadherin and the alpha E beta 7 integrin. Nature 372 , 190-193 (1994).

16. Schon, M.P. et al. Mucosal T lymphocyte numbers are selectively reduced in integrin alpha E (CD103)-deficient mice. J. Immunol. 162, 6641-6649 (1999).

17. Lehmann, J. et al. Expression of the integrin alpha Ebeta 7 identifies unique subsets of CD25 + as well as CD25- regulatory T cells. Proc. Natl. Acad. Sci. USA 99, 13031-13036 (2002).

18. Iwata, M. Retinoic acid production by intestinal dendritic cells and its role in T-cell trafficking. Semin. Immunol. 21, 8-13 (2009).

19. Gratas, C., Menot, M.L., Dresch, C. \& Chomienne, C. Retinoid acid supports granulocytic but not erythroid differentiation of myeloid progenitors in normal bone marrow cells. Leukemia 7, 1156-1162 (1993).

20. Robertson, K.A., Emami, B., Mueller, L. \& Collins, S.J. Multiple members of the retinoic acid receptor family are capable of mediating the granulocytic differentiation of HL-60 cells. Mol. Cell. Biol. 12, 3743-3749 (1992).

21. Tsai, S. \& Collins, S.J. A dominant negative retinoic acid receptor blocks neutrophil differentiation at the promyelocyte stage. Proc. Natl. Acad. Sci. USA 90, 7153-7157 (1993).

22. Iwata, M. et al. Retinoic acid imprints gut-homing specificity on T cells. Immunity 21, 527-538 (2004).

23. Mora, J.R. et al. Generation of gut-homing IgA-secreting B cells by intestinal dendritic cells. Science (New York, NY) 314, 1157-1160 (2006).

24. Stephensen, C.B. Vitamin A, infection, and immune function. Annu. Rev. Nutr. 21, 167-192 (2001).

25. Napoli, J.L. Quantification of physiological levels of retinoic acid. Methods Enzymol. 123, 112-124 (1986).

26. Ishibashi, K., Kanno, E., Itoh, T. \& Fukuda, M. Identification and characterization of a novel Tre-2/Bub2/Cdc16 (TBC) protein that possesses Rab3A-GAP activity. Genes Cells 14, 41-52 (2009).

27. Nelson, D.R. A second CYP26 P450 in humans and zebrafish: CYP26B1. Arch. Biochem. Biophys. 371, 345-347 (1999).
28. Haeseleer, F., Huang, J., Lebioda, L., Saari, J.C. \& Palczewski, K. Molecular characterization of a novel short-chain dehydrogenase/reductase that reduces all-trans-retinal. J. Biol. Chem. 273, 21790-21799 (1998)

29. Kiss, $\mathrm{H}$. et al. The LZTFL1 gene is a part of a transcriptional map covering $250 \mathrm{~kb}$ within the common eliminated region 1 (C3CER1) in 3p21.3. Genomics 73, 10-19 (2001).

30. Cooley, J., Takayama, T.K., Shapiro, S.D., Schechter, N.M. \& RemoldO'Donnell, E. The serpin MNEl inhibits elastase-like and chymotrypsin-like serine proteases through efficient reactions at two active sites. Biochemistry 40, 15762-15770 (2001).

31. Lim, S.P., Leung, E. \& Krissansen, G.W. The beta7 integrin gene (Itgb-7) promoter is responsive to TGF-beta1: defining control regions. Immunogenetics 48, 184-195 (1998).

32. Gorelik, L. \& Flavell, R.A. Abrogation of TGFbeta signaling in T cells leads to spontaneous $T$ cell differentiation and autoimmune disease. Immunity 12, 171-181 (2000).

33. Kunkel, E.J. et al. Lymphocyte CC chemokine receptor 9 and epithelial thymus-expressed chemokine (TECK) expression distinguish the small intestinal immune compartment: epithelial expression of tissue-specific chemokines as an organizing principle in regional immunity. J. Exp. Med. 192, 761-768 (2000).

34. Wurbel, M.A. et al. The chemokine TECK is expressed by thymic and intestinal epithelial cells and attracts double- and single-positive thymocytes expressing the TECK receptor CCR9. Eur. J. Immunol. 30, 262-271 (2000).

35. Hosoe, N. et al. Demonstration of functional role of TECK/CCL25 in T lymphocyte-endothelium interaction in inflamed and uninflamed intestinal mucosa. Am. J. Physiol. Gastrointest. Liver Physiol. 286, G458-466 (2004).

36. Stenstad, H. et al. Gut-associated lymphoid tissue-primed CD4 + T cells display CCR9-dependent and -independent homing to the small intestine. Blood 107, 3447-3454 (2006).

37. Humphries, M.J. Integrin structure. Biochem. Soc. Transac. 28, 311-339 (2000).

38. Z'Graggen, K., Walz, A., Mazzucchelli, L., Strieter, R.M. \& Mueller, C. The C-X-C chemokine ENA-78 is preferentially expressed in intestinal epithelium in inflammatory bowel disease. Gastroenterology 113, 808-816 (1997).

39. Zeller, Y., Lohr, J., Sammar, M., Butcher, E.C. \& Altevogt, P. Asp-698 and Asp-811 of the integrin alpha4-subunit are critical for the formation of a functional heterodimer. J. Biol. Chem. 273, 6786-6795 (1998).

40. DeNucci, C.C., Pagan, A.J., Mitchell, J.S. \& Shimizu, Y. Control of alpha4beta7 integrin expression and CD4 T cell homing by the beta1 integrin subunit. J. Immunol. 184, 2458-2467 (2010).

41. Nakamura, K. et al. TGF-beta 1 plays an important role in the mechanism of CD4 + CD25 + regulatory T cell activity in both humans and mice. J. Immunol. 172, 834-842 (2004).

42. Guagnozzi, D. \& Caprilli, R. Natalizumab in the treatment of Crohn's disease. Biologics 2, 275-284 (2008).

43. Stefanelli, T., Malesci, A., De La Rue, S.A. \& Danese, S. Anti-adhesion molecule therapies in inflammatory bowel disease: touch and go. Autoimmun. Rev. 7, 364-369 (2008).

44. Berger, J.R. \& Koralnik, I.J. Progressive multifocal leukoencephalopathy and natalizumab--unforeseen consequences. N. Engl. J. Med. 353, 414-416 (2005).

45. Kleinschmidt-DeMasters, B.K. \& Tyler, K.L. Progressive multifocal leukoencephalopathy complicating treatment with natalizumab and interferon beta-1a for multiple sclerosis. N. Engl. J. Med. 353, 369-374 (2005).

46. Keusch, G.T. Micronutrients and susceptibility to infection. Ann. NY Acad. Sci. 587, 181-188 (1990).

47. Schweigert, F.J. Inflammation-induced changes in the nutritional biomarkers serum retinol and carotenoids. Curr. Opin. Clin. Nutr. Metab. Care 4, 477-481 (2001).

48. Uehara, S., Grinberg, A., Farber, J.M. \& Love, P.E. A role for CCR9 in T Iymphocyte development and migration. J. Immunol. 168, 2811-2819 (2002).

49. Kang, S.G., Wang, C., Matsumoto, S. \& Kim, C.H. High and low vitamin A therapies induce distinct FoxP3 + T-cell subsets and effectively control intestinal inflammation. Gastroenterology 137, 1391-1402 e1391-1396 (2009).

50. Kang, S.G. et al. Identification of a chemokine network that recruits FoxP3 $(+)$ regulatory $T$ cells into chronically inflamed intestine. Gastroenterology 132, 966-981 (2007). 